\title{
Interannual Variability of the Occurrence of MJO at Different Phases and Its Association with Two ENSO Modes
}

\section{Panini Dasgupta ( $\sim$ panini.dasgupta@tropmet.res.in )}

Centre for Climate Change Research, Indian Institute of Tropical Meteorology, Ministry of Earth Sciences, Pune 411008

\section{Roxy Koll}

Centre for Climate Change Research, Indian Institute of Tropical Meteorology, Ministry of Earth Sciences,

Pune 411008

\section{Rajib Chattopadhyay}

Indian Institute of Tropical Meteorology, Ministry of Earth Sciences, Pune 411008

\section{Chennu Naidu}

Department of Meteorology and Oceanography, College of Science \& Technology, Andhra University,

Visakhapatnam, Andhra Pradesh 530003

\section{Abirlal Metya}

Centre for Climate Change Research, Indian Institute of Tropical Meteorology, Ministry of Earth Sciences, Pune 411008

\section{Research Article}

Keywords: MJO, RMM, ENSO, PCA

Posted Date: November 30th, 2020

DOl: https://doi.org/10.21203/rs.3.rs-112899/v1

License: (c) (i) This work is licensed under a Creative Commons Attribution 4.0 International License.

Read Full License 


\section{Interannual variability of the occurrence of MJO at different 2 phases and its association with two ENSO modes}

3 Panini Dasgupta ${ }^{1,2^{*}}$, M K Roxy ${ }^{1}$, Rajib Chattopadhyay ${ }^{3}$, C. V. Naidu ${ }^{2}$, Abirlal Metya ${ }^{1,4}$

$4 \quad{ }^{1}$ Centre for Climate Change Research, Indian Institute of Tropical Meteorology, Ministry of Earth

5 Sciences, Pune 411008, India

$6{ }^{2}$ Department of Meteorology and Oceanography, College of Science \& Technology, Andhra University,

$7 \quad$ Visakhapatnam, Andhra Pradesh 530003, India

$8{ }^{3}$ Indian Institute of Tropical Meteorology, Ministry of Earth Sciences, Pune 411008, India

$9{ }^{4}$ Department of Atmospheric and Space Sciences, Savitribai Phule Pune University, Pune, India

10 *Correspondence to panini.dasgupta@tropmet.res.in

11

12

13

14

15

16

17

18

19 
21 In the present study, we investigate the interannual variability of the occurrence of the Madden Julian 22 Oscillation (MJO) at different Real-time Multivariate MJO (RMM) phase regions (MJO frequency) and its

23 association with the El Niño Southern Oscillation (ENSO). Evaluating the all-season data, we identify the 24 dominant zonal patterns of MJO frequency exhibiting prominent interannual variability. Using Principal 25 Component Analysis Biplot (PCA Biplot) technique, we demonstrate that the MJO frequency has two 26 distinct modes of variability related to RMM1 and RMM2 spatial patterns. The first spatial mode of MJO 27 frequency related to RMM1 is associated with a higher frequency of MJO active days over the Maritime 28 Continent and a lower frequency over the central Pacific Ocean and the western Indian Ocean, or vice versa. 29 The second mode related to RMM2 is associated with a higher frequency of MJO active days over the 30 eastern Indian Ocean and a lower frequency over the western Pacific, or vice versa. We find that these two 31 types of MJO frequency patterns are associated with the central Pacific and eastern Pacific ENSO modes, 32 respectively. These MJO frequency patterns are the lag response of the underlying ocean state.

\section{Introduction}

35 The Madden Julian Oscillation (MJO) and El Niño Southern Oscillation (ENSO) are the two strongest 36 modes in intraseasonal and interannual time scales, and hence of immense importance to the global climate 37 variability ${ }^{1-4}$. The MJO is evident by the slow eastward propagating tropical convective branch which 38 usually originates over the western Indian Ocean and dies out over the cold sea surface temperature (SST) 39 beyond the dateline. Based on outgoing longwave radiation (OLR) and zonal wind at $850 \mathrm{hPa}$ and $200 \mathrm{hPa}$, 40 Wheeler and Hendon ${ }^{5}$ derived a Real-time Multivariate MJO index (RMM) to track the dynamical and 41 convective signal of the MJO. The eight phases of the RMM index represent the location of active 42 convection of MJO over the tropics. RMM index has been extensively used to explore the role of the MJO 43 in various weather and climate phenomena.

44 Importantly, the MJO possesses profound seasonal characteristics. MJO is strongest during boreal 45 winter and spring (December-January-February and March-April-May) and weakest during boreal summer 46 and autumn (June-July-August and September-October-November) ${ }^{6,7}$. The number of MJO events also 47 varies according to seasons. Location of the MJO signal shifts southward and northward in boreal winter 48 and summer, respectively ${ }^{8,9}$. 
Despite belonging to widely separated time scales, the MJO and ENSO have profound similarities

50 in large scale convection and circulation patterns. These similarities have led to extensive studies on the 51 connection between the MJO and ENSO in the past few decades ${ }^{10-12}$. These studies suggest that the overall 52 MJO amplitude or strength of the MJO convection is not appreciably affected by the presence of an El Niño 53 or a La Niña. They suggest that the mature El Niño or La Niña phase only expands the region of MJO 54 activity further eastward or westward ${ }^{13}$. The inter-annual variation of MJO is therefore observed along the 55 boundaries of the intra-seasonal variability center. Besides this simultaneous connection between the MJO 56 and ENSO, Hendon et al. ${ }^{14}$ observed a lag relationship between the MJO activity in spring (March-April57 May) and the state of ENSO in subsequent winter (December-January-February). This explains the role of 58 MJO in the initiation of ENSO events. Pang et al. ${ }^{15}$ examined the effects of two types of ENSO, i.e., 59 canonical and central Pacific warm-cold events on boreal winter MJO. They observed that the MJO strength 60 is generally weaker during the canonical warm period and stronger during the canonical cold period. The 61 case is opposite for central Pacific ENSO events where the MJO strength is generally stronger during warm 62 phases and is weaker during central Pacific cold phases. Overall, these studies are mainly focused on the 63 interannual variation of the strength of MJO convection or the amplitude. Similar to the MJO amplitude, 64 the number of MJO active days (frequency of occurrence) also undergoes through interannual variations 65 which has different characteristics than of the MJO intensity ${ }^{16}$. The frequency of occurrence in different 66 phase locations in a season is also affected by the two ENSO types ${ }^{15}$. For example, the frequency of 67 occurrence in phase 2,3 and 4,5 increases during eastern Pacific and central Pacific El Niño warm phases 68 respectively.

ENSO is known to have global impacts during its extreme phases. The dynamical interaction between tropics and extra-tropics are believed to be the major reason behind the large-scale ENSOteleconnection pattern. Similar to ENSO, the MJO also has large scale teleconnections in its certain phases (mainly in phase 3 and 7) of its propagation ${ }^{13}$. Recent studies suggest that the seasonal MJO activity over the Indian Ocean and western Pacific can influence North Atlantic Oscillation (NAO), Pacific North America pattern (PNA) and Atlantic Meridional Oscillation (AMO) through teleconnections ${ }^{17}$. Seasonal MJO activity, therefore, is an important factor to be understood properly to comprehend the MJO teleconnections.

In most of the earlier studies, the inter-annual variability of MJO and its relation to ENSO were 78 mainly investigated by examining any particular season i.e. boreal winter, spring or summer ${ }^{17,18}$. ENSO 79 evolution, however, starts from boreal autumn (September-October-November), matures during boreal 80 winter (December-January-February) and decays during the subsequent boreal spring. Therefore, it is 81 important to examine interannual variability of MJO and its relation to ENSO considering all the seasons. 82 Secondly, previous studies majorly focused on the intensity of MJO (variance in intra-seasonal OLR) for 
studying the inter-annual variability of the MJO. However, recent studies ${ }^{16,19-21}$ demonstrate that interannual

84 variability of the $\mathrm{MJO}$ is more evident in the variation in the number of days $\mathrm{MJO}$ convection spent over

85 the certain region (i.e. the frequency of occurrences of MJO phases) rather than its amplitude. The signature

86 of MJO phase occurrence in a season is evident through the seasonal mean convective activity over the

87 respective phase regions. In the present study, we examined the inter-annual variability of the MJO in terms

88 of the frequency of occurrence of the MJO phases, where we consider MJO activity in all four conventional

89 seasons. The major goal of the present study is to find dominant spatial modes of MJO variability. We have

90 employed multivariate Principal Component Analysis (PCA) and PCA Biplot to visualize and interpret our

91 results. Biplot technique to visualize the PCA result is not very common in meteorology. We have tried to

92 implement this method for examining the inter-annual variability of MJO frequency.

\section{Results}

\section{Dominant Modes of interannual variability of MJO Frequency anomaly}

95 Eight phase locations of MJO depict the different sections of the tropics through which the MJO propagates.

96 Phase regions 1 to 3 represent west to central tropical Indian Ocean. Phase regions 4 and 5 depict the eastern

97 Indian Ocean and Maritime Continent. Phases 6 to 8 represent west to central tropical Pacific region.

98 MJO frequency anomalies at the eight MJO phase locations in a season explain the spatial variation 99 of MJO activity. In this study, we tried to identify the coherent MJO phase locations which undergo a 100 similar interannual variation of MJO. We call this coherent MJO frequency variations in different phase 101 locations as the spatial modes of MJO frequency variation. We identified these spatial modes by employing 102 EOF analysis on MJO frequency anomaly data (Fig. 1a).

103 Fig. $1 \mathrm{~b}$ represents the percentage of variance explained by the eight EOFs of MJO frequency 104 anomaly. It is important to note that the first two EOFs explain almost half $(48 \%)$ of the total variance in 105 MJO frequency anomaly. EOF1 and EOF2 explain about $25.7 \%$ and $22.2 \%$ of the total variance. The 106 remaining EOFs explain the rest of the variability with nearly equal contributions. The first two EOFs are 107 significantly separated from each other and rest of the EOFs according to North et al. ${ }^{22}$ criteria. The spatial 108 pattern of the first two EOFs is represented in Fig. 1c,d. We find that these structures of the first two EOFs 109 do not change appreciably over time (Supplementary Fig. 3).

110 EOF1 represents an out of phase pattern of MJO frequency anomaly between the phase regions 1, 2, 8 and $1114,5,6$ (Fig. 1c). This means that a positive MJO frequency anomaly at phase regions 1, 2, and 8 (west to 112 central Indian Ocean) coincide with negative (opposite) MJO frequency anomaly in phase regions 4, 5 and 1136 (eastern Indian Ocean to the Maritime Continent to the western Pacific). The MJO frequency anomaly 114 variations at phase 3 (central Indian Ocean) and 7 regions (west-central Pacific) are less in this variation 
115 pattern. Phase 1 (western Indian Ocean) and 5 (Maritime Continent) MJO frequency variations are most 116 dominant in EOF1. The structure of EOF1 pattern is similar to RMM1 spatial pattern (Fig. 1c). The second 117 EOF also denotes a similar out-of-phase relationship of MJO frequency anomaly between phase regions 2 , 118 3, 4 (central to east Indian Ocean) and 6, 7, 8 (west to central Pacific) (Fig. 1d). In the second EOF structure, 119 MJO frequency anomaly is small over phase regions 1, 5 (western Indian Ocean and Maritime Continent) 120 and are mostly in phase regions 3, 7 (central Indian Ocean and western Pacific). The structure of EOF2 121 pattern is similar to RMM2 spatial pattern.

122 MJO frequency variation (interannual variation) at the eight phase locations and there inter123 relationship, can be visualized in terms of the two leading EOFs forming a two-dimensional plane through 124 the biplot technique (Fig. 1e,f). We discussed the details of biplot in the method section. MJO frequency 125 anomaly variation at the eight phase locations are represented by the eight arrows in the biplot. Precisely, 126 the length of an arrow represents the variance of MJO frequency in a certain phase location explained by 127 the two leading EOFs (Fig. 1e). An arrow's direction depends on the correlation of MJO frequency variation 128 at a location with two EOF time series. It tells the extent to which the frequency variation in a certain phase 129 is closely related to either of the spatial modes. As we can see, MJO frequency variation at phase locations 1301 and 5 are closely related to EOF1 spatial modes. Similarly, MJO frequency variation at phase regions 3 131 and 7 are related to EOF2 spatial modes. The MJO frequency variations at these phase locations provide 132 maximum variance to the MJO frequency spatial modes.

133 The arrows which group together by having the same direction in the two-dimensional plane, 134 represent the positively correlated MJO phase locations having similar MJO frequency variations. The 135 cosine of the angle between two arrows denotes the correlation among MJO frequency variations in the 136 corresponding two-phase locations. From Fig. 1e,f, we observe that the MJO frequency variations at phase 137 locations 1, 2, 7 and 8 are negatively correlated with the variation at phases 5, 6, 3 and 4 respectively (as 138 it also seen in Fig. 1c,d). This in-between relationship among MJO frequency variations at eight phase 139 regions can be also observed in the quadrants of the RMM phase diagram. This means that a positive MJO 140 frequency anomaly in a particular phase region is also associated with the negative MJO frequency anomaly 141 at the opposite phase quadrant in RMM phase diagram.

142 We obtained correlation coefficients and cosine square, two statistical quantities, to quantify the 143 goodness of representation of the MJO frequency variation through the leading EOFs. The cosine square 144 parameter represents the percentage of the variance of MJO frequency over a location expressed through a 145 certain EOF (Fig. 1e). The sum of cosine square values for all the EOFs is equal to 1. We also measured 146 the correlation coefficient between MJO frequency time series at eight phase locations and the EOF time 147 series to obtain the goodness of representation of MJO frequency data by the two leading EOFs. In Table 1 148 the correlation coefficient and cosine square values are represented. The significant correlation value for 
149156 data points at $99 \%$ confidence level is 0.21 . Considering the cosine square and correlation coefficient,

150 we observed that EOF1 well represents the MJO frequency variation at phase locations 1, 2, 5, and 6 (where 151 correlation values exceeds 0.5). Similarly, EOF2 represents the MJO frequency variation in phase 3, 4, 7

152 and 8 (Table 1). From correlation coefficients and cosine square values, it becomes reasonable to study the

153 MJO frequency variations in terms of these two spatial EOF modes. MJO frequency in terms of two leading

154 EOF modes also is a dimension reduced form ( 8 dimensions to 2 dimensions) of MJO frequency anomaly

155 data which is easier to be analyzed than higher dimensional data.

156 Frequency modes and its relation with seasonal mean SST anomaly, intraseasonal OLR and 157 precipitation

158 To examine the effect of the MJO frequency modes in terms of intraseasonal convection (OLR), we 159 calculated the correlation between seasonal mean filtered OLR (20-100 days filtered) and PC1 and PC2 of 160 MJO frequency. (Fig. 2 a,b). MJO frequency anomaly represents the change in the number of MJO 161 convective days. A change in the number of convective days is generally expected to be evident in seasonal 162 mean OLR rather than the variance of the OLR in a season. The variance of filtered OLR refers to the 163 strength or amplitude of MJO convection whereas a negative mean of filtered OLR expresses the fact that 164 significant part of the signal represented the negative OLR anomaly leading to a higher number of 165 convective days. The filtered OLR patterns correlated with EOF1 and EOF2 is presented in Fig. 2a,b. We 166 obtained the correlated MJO precipitation (space-time filtered) anomaly associated with PC1 and PC2 in 167 Fig. 2c,d. The correlated filtered OLR and precipitation pattern for EOF1 (Fig. 2a,c) shows wet western 168 Indian Ocean and central-east Pacific, when the Maritime Continent and western Pacific regions are dry, 169 and vice versa. The correlated filtered OLR and precipitation pattern for the second mode denotes the wet 170 eastern Indian Ocean when the western Pacific is dry and vice versa (Fig. 2b,d).

171 To examine the mean state of the tropical ocean associated with the MJO frequency modes, we 172 obtained the correlated seasonal mean SST anomalies of EOF1 and EOF2 time series (Fig. 2e,f). We 173 observed that the first MJO frequency mode (EOF1) is apparently related to central Pacific warm event 174 structure or El Niño Modoki structure (Fig. 2e, Ashok et al. ${ }^{23}$ ). The correlation between PC1 (2-8 years 175 filtered) and CP ENSO index is significant at 95\% confidence level with a correlation value 0.24 (Fig. 2g; 176 here spatial pattern is related to unfiltered PC1). The associated SST pattern with the second MJO frequency 177 mode (EOF2) shows an EP-type canonical ENSO pattern. The correlation between PC2 (2-8 years filtered) 178 and EP ENSO index is significant at 95\% confidence level with correlation value 0.47 (Fig. 2h; here spatial 179 pattern is related to unfiltered PC2). We further examined the lead-lag correlation between PC1 (2-8 years 180 filtered) and CP ENSO index, where we found that the CP ENSO index leads PC1 MJO frequency pattern 181 by one season ( 3 months) with peak correlation value 0.27 . At lag 0 the correlation is approximately 0.24 
182 (Fig. 3). From the lead-lag relationship between PC2 time series (2-8 years bandpass filtered) and EP ENSO

183 index, we found that the EP ENSO index leads PC2 timeseries by one season with peak correlation value

1840.52 (Fig. 3). At lag 0 the correlation is approximately 0.47 (Fig. 3). Apparently, these MJO frequency

185 patterns fully establish in response to the underlying ocean condition at a 3 months lag. The reason for the

186 weak correlation between PC1 (2-8 years filtered) and CP ENSO index may be due to the sample size in

187 our present study. ENSO is a 2-8 years event and the number of ENSO events during 1979-2018 are few.

188 Generally, the SST variability in the central Pacific is not as large as in the east Pacific, which may also 189 have a bearing on the correlation. The time series of PC1 (2-8 years filtered), CP ENSO index and PC2, EP

190 ENSO index are represented in Fig. $2 \mathrm{~g}$,h. These time series plots show significant associations between 191 two MJO frequency modes and two ENSO types.

192 Since a correlation analysis may not clearly represent the relationship between MJO frequency 193 modes and two ENSO types, we have done composite analysis for CP-type and EP-type El Niño/La Niña 194 years in the next section.

\section{Composites of MJO frequency during canonical and Central Pacific warm and cold events}

196 The association between two types of ENSO modes and MJO frequency modes are further examined 197 through a composite analysis. Composites of MJO frequency anomaly during EP -type canonical warm/cold 198 and central Pacific warm/cold seasons are prepared. If the modes are associated with two respective types 199 of ENSO, then composites of frequency anomaly during these ENSO phases should match with the EOF 200 MJO frequency patterns. We observed the MJO frequency composites during warm and cold CP-type 201 ENSO phases and their composite differences resemble EOF1 MJO frequency pattern (Fig. 4a,c,e). 202 Similarly, MJO frequency composites during warm and cold EP-type canonical ENSO events and their 203 differences resemble EOF2 MJO frequency pattern (Fig. 4b,d,f). These composites reveal a possible 204 association between two frequency modes and two types of ENSO events.

205 MJO frequency variation through biplot and clusters

206 The relation between MJO frequency and ENSO phases are explored from a different perspective using the 207 biplot technique. We represent 156 season's MJO frequency data in a two-dimensional plane where MJO 208 frequency EOFs are the axes (Fig. 4g,h). In the biplot diagram, MJO frequency in a particular season is 209 represented by a point where its location is estimated by the standardized amplitude of EOF time series. 210 The points in a biplot basically represent a scatterplot in two dimensional EOF plane. MJO frequency points 211 which make a cluster in the biplot space have similar projections on two EOF modes which denotes the fact 212 that seasons had similar MJO frequency anomalies. Distance between two points in biplot space is called 213 Mahalanobis distance ${ }^{24}$, indicating the statistical similarity between the points representing MJO events. 
215 (Supplementary Fig. 1) representing the warm, cold and neutral central Pacific CP-type and canonical EP216 type ENSO phases. The points representing a particular class is enclosed by the data ellipse which explains 217 the overall statistics of the points (Fig. 4g,h) in the biplot space. The joint distributions of standardized 218 principal components i.e. PC1 and PC2 for three classes are also represented in Fig. 4g,h. The mean, 219 standard deviation and correlation of PC1 and PC2 for different classes are represented in Table2.

In Fig. 4g, data ellipses represent warm, cold and neutral CP-type ENSO phases. It is observed from the Fig. 4g that from cold to warm CP-type ENSO phases, the center (mean state) of the data ellipse 222 shifts from negative to positive EOF1 axis. This fact is also evident from the probability distribution of 223 EOF1 amplitude during positive, negative and neutral CP-type ENSO phases. It can be seen that the mean 224 of distribution shift from negative EOF1 axis to positive EOF1 axis. This means that positive MJO 225 frequency anomalies are seen at MJO phase regions 1, 2 and 8 (the western Indian Ocean and central 226 Pacific) and negative MJO frequency anomalies are seen at phase regions 5 and 6 (Maritime continent) 227 during warm central Pacific ENSO phases. This MJO frequency anomaly pattern gets reversed during the negative phase of central Pacific ENSO.

Similar to CP-type ENSO phases, three clusters of EP-type ENSO phases are presented in Fig. 4h. In contrast to the case of CP-type ENSO phases, the center of the data ellipse shift from negative EOF2 axis to positive EOF2 axis during canonical EP-type ENSO negative to a positive phase. The shifts in data ellipses centers are associated with the mean MJO frequency pattern changes during cold to warm EP-type ENSO phases. In the case of EP-type ENSO phases, overall MJO frequency changes following the EOF2 axis. This means that positive MJO frequency anomalies are seen at MJO phase regions 3 and 4 (centraleast Indian Ocean) and negative MJO frequency anomalies are seen at phase regions 6 and 7 (west to central Pacific) during warm canonical ENSO period. This MJO frequency anomaly pattern gets reversed during the negative EP-type ENSO period. The warm and cold EP-type ENSO data ellipse has directions along with MJO phases 4, 8 and MJO phases 2, 6, respectively. This means that during the canonical warm period, MJO frequencies in phase regions 4 and 8 have the highest variability. Either of the phase region 4 (eastern Indian Ocean) or phase region 8 (central Pacific) may have large MJO frequency anomaly. Similarly, during the canonical La Niña, either of the phase region 2 (central Indian Ocean) or phase region 6 (western Pacific) may have large MJO frequency anomaly. basic state change of MJO frequency pattern. These basic state changes in the MJO frequency pattern associated with the ENSO modes are the possible reasons behind the observed correlation between MJO frequency EOFs and two type ENSO indices. It is important to note that time series of two modes of MJO 
247 variability follows normal distribution at a 99\% confidence level as evident in D'Agostino and Pearson's 248 test.

\section{Composite differences between central Pacific and eastern Pacific warm and cold events}

250 The composite differences of SST, filtered OLR, space-time filtered precipitation, vertically integrated

251 MSE, MSE tendency, zonally averaged circulation and specific humidity between the warm and cold phases

252 of the CP-type ENSO are represented in Fig. 5a,c,e,g,I,k. Similarly, composite differences for EP-type

253 ENSO are represented in Fig. 5b,d,f,h,j,l. We derived the composite differences of different parameters

254 between the warm and cold phases of ENSO to investigate the reason for basic state shift of MJO activity

255 following the MJO frequency EOF patterns.

256 For the CP-type ENSO, the composite differences between warm and cold phases indicate the 257 enhanced intraseasonal precipitation at the western Indian Ocean and central Pacific (RMM phase 1,2 and 258 8) and suppressed intraseasonal precipitation over the maritime continent (RMM phase 5 and 6) which is 259 similar with the MJO frequency EOF1 pattern (Fig. 5a,c,e). The outcome from the biplot of CP-type ENSO 260 phases also suggest the mean state change following the MJO frequency EOF1 pattern. For the EP-type 261 ENSO, the composite differences between warm and cold phases show the enhanced intraseasonal rainfall 262 near eastern equatorial Indian Ocean and maritime Continent and suppressed intraseasonal rainfall over 263 west-central Pacific Ocean. This is also consistent with the MJO frequency EOF2 pattern and biplot 264 outcome for EP-type ENSO phases (Fig. 5b,d,f).

To investigate the reason for the particular MJO frequency anomaly patterns associated with the 266 two types ENSO phases, we examined the composite differences of vertically integrated intraseasonal MSE 267 anomalies, vertically integrated intraseasonal MSE tendencies, zonally averaged circulation and specific 268 humidity profiles in Fig. 5g-1. For CP-type ENSO phases there are negative intraseasonal MSE anomalies 269 over the maritime continent (RMM phases 5 and 6) and positive MSE anomalies over the west and central 270 Indian Ocean (RMM phases 1and 3) and Central Pacific (RMM phase 8) (Fig. 5g). The negative tendency 271 of intra-seasonal MSE is also observed over the maritime continent (the same region with negative MSE 272 anomalies) decreasing the lifetime of MJO over the maritime continent. The positive MSE tendency is 273 observed over the west-central Indian Ocean and central Pacific enhancing the MJO lifetime over these 274 regions. We find that the mean zonal circulation favors the convection over the western Indian Ocean and 275 the central Pacific Ocean and opposes convection over the Maritime Continent during the CP-type ENSO 276 events (Fig. 5i). During these times, the main descending branch of the Walker circulation is situated over 277 the eastern equatorial Indian Ocean and maritime continent centering at $120^{\circ} \mathrm{E}$. The mean moisture 278 distribution (specific humidity) over the maritime continent shows the negative anomalies centered at $120^{\circ}$ 279 E following the zonal circulation pattern (Fig. 5k). Therefore, the mean background moisture distribution 
is a vital factor determining the intraseasonal MSE tendency. The intraseasonal MSE tendency term generally depends on the advection of mean background moisture by intraseasonal easterly winds. For the CP-type ENSO seasons, negative background moisture anomalies over the Maritime Continent creates negative intraseasonal MSE tendency which restricts the MJO propagation over these regions.

In the case of canonical EP-type ENSO phases, the main descending branch of the Walker circulation is situated over the maritime continent and western Pacific at the east of $120^{\circ} \mathrm{E}$ (Fig. 5j). The mean moisture distribution (specific humidity) over the maritime continent and west Pacific shows the negative anomalies at the east of $120^{\circ} \mathrm{E}$ following the zonal circulation pattern (Fig. 51). Therefore, the intraseasonal MSE tendency term is negative over the maritime continent and west Pacific, restricting the MJO propagation over these regions (Fig. 5h). The intra-seasonal MSE tendency over the eastern Indian ocean is positive due to the moisture contribution from western pacific surface divergence. Vertically integrated intraseasonal MSE anomalies are positive over the central and eastern Indian Ocean and negative at the east of $120^{\circ} \mathrm{E}$ following the intra-seasonal MSE tendency pattern. Therefore, during the EP-type ENSO phases, positive intraseasonal precipitation anomalies are observed at central and eastern equatorial the Indian Ocean and negative intraseasonal precipitation anomalies are observed over the western and central Pacific.

\section{MJO propagation during the central Pacific and eastern Pacific warm and cold events}

297 We further investigated the propagation features of intraseasonal OLR during the warm and cold phases of 298 CP-type and EP-type ENSO events. In Fig. 6, lag-longitude propagations of OLR during CP-type and EP299 type warm (shaded anomalies) and cold phases (contoured anomalies) are represented. Here we calculated 300 the lag-propagation of OLR with respect to the central Indian Ocean $\left(80^{\circ} \mathrm{E}-90^{\circ} \mathrm{E}, 15^{\circ} \mathrm{S}-15^{\circ} \mathrm{N}\right)$. We also 301 identified location (longitude) of maximum cross-correlation at each time lags. These locations roughly 302 provide an idea about how much time MJO has spent at each of the longitudes. At times when the location 303 of maximum correlation stays at same longitude for consecutive timesteps, it denotes that the MJO 304 convection is spending a longer time over that particular longitude (more MJO frequency over that 305 longitude). For the CP-type negative phases, we find that the MJO spends more time around $120^{\circ} \mathrm{E}(13$ 306 days) compared to CP-type positive phases (6 days). Similarly, for the EP-type negative phases, MJO

307 spends more time over the maritime continent and western Pacific between $110^{\circ} \mathrm{E}-150^{\circ} \mathrm{E}(11$ days $)$ 308 compared to EP-type positive phases (5 days). During the EP-type positive phases, MJO spends more time 309 at central and eastern equatorial Indian ocean between the $80^{\circ} \mathrm{E}-100^{\circ} \mathrm{E}$ ( 16 days) compared to the EP-type 310 negative phases (12 days). This representation approximately provides the differences in the MJO 311 propagations between the warm and cold ENSO phases. 


\section{Discussion}

313 The relationship between the MJO and ENSO has been studied rigorously in the past few decades which 314 comprehended many aspects of their connection. Interannual variability of the MJO can be quantified in 315 terms of the frequency of occurrence of the MJO phases. Interannual variability of MJO frequency at the 316 eight MJO phases (MJO frequency) represent the information on the spatial variability of the MJO. The

317 MJO activity may vary over the warm pool region in a season. Barrier effect is one of the examples of this 318 type of variation where the MJO do not propagate through the Maritime Continent and dissipate over the 319 region. In that case, the number of MJO convective days over the eastern Indian Ocean becomes different 320 from the Western Pacific Ocean due to the lack of MJO propagation beyond the Maritime Continent.

This idea of spatial asymmetry of the MJO activity and its interannual variability leads us to investigate the interannual variability of the MJO frequency over different phase regions. In the present study, we have used an EOF technique on the MJO frequency anomaly data for 156 seasons from 19792018. We have used the EOF technique to identify the spatially correlated MJO frequency variability pattern. From the EOF analysis, we find that there are two dominant spatial modes of MJO frequency anomaly present which have significant interannual variation (Fig. 1). These two spatial modes of the MJO frequency explain almost half of the interannual variability of MJO frequency. Interestingly, both of the leading EOFs of MJO frequency have out-of-phase dipole structure that indicates the spatially asymmetric nature of the variability of MJO frequency. The first EOF of the MJO frequency variation shows a reduced number of MJO active days over the maritime continent, with increased MJO active days over the central Pacific Ocean and western Indian Ocean, or vice versa. The second mode of the MJO phase frequency is associated with higher number of MJO active days over the eastern Indian Ocean when the MJO active days over the western Pacific is less than normal or vice versa. The EOFs and their explained variances suggest that interannual variability of MJO frequency is majorly contributed by these two asymmetric MJO frequency pattern. By knowing the amplitudes of the two MJO frequency EOFs in a season, we can assume the MJO frequency anomaly in that season. We regressed seasonal mean OLR on the two MJO frequency EOFs' time series to observe the EOFs in terms of seasonal mean convection could be the tropical SST or large-scale circulations, or it could be due to the internal dynamics of the atmosphere. The role of tropical SST on these two modes is investigated further by observing the linear correlation between the time series of the EOF modes and seasonal average tropical SST conditions (Fig. value 0.24 significant at $95 \%$ confidence level) whereas the second spatial mode is significantly correlated to canonical ENSO state (with correlation value 0.47 significant at $95 \%$ confidence level). Further the lead- 
345 lag correlation analysis suggests that these two MJO frequency modes lags the underlying SST condition 346 by one season. Since, the correlation values are not large, so it is not right to jump into the conclusion that 347 the two ENSO modes are responsible for the two respective MJO frequency EOFs. We, therefore, 348 conducted a composite analysis of MJO frequency anomaly during positive and negative phases of central 349 Pacific and eastern Pacific ENSO seasons. A major association of the MJO frequency with these two types 350 of ENSO modes should make the composites of MJO frequency anomaly look like the two MJO frequency 351 EOF patterns. The composites of MJO frequency anomaly during the central Pacific and eastern Pacific 352 ENSO seasons are similar to MJO frequency EOF1 and EOF2 respectively, suggesting that there is a 353 significant relationship between the MJO frequency EOFs and ENSO modes.

354 Hence, we tried to understand the interannual variability of the MJO frequency in terms of the two 355 leading EOFs of MJO frequency through the biplot technique (Fig. 1,3). Basically, this representation is 356 the scatter plot in two-dimensional leading EOF plane. MJO frequency anomalies for each of the 156 357 seasons is represented as a position vector in two dimensional EOF plane. The combination of the MJO 358 frequency modes represents the estimate of frequency anomaly in a particular season. We drew data ellipses 359 enclosing the MJO frequency anomaly during central Pacific and canonical ENSO positive and negative 360 states. We find that from the central Pacific cold to warm ENSO state, the mean MJO frequency pattern 361 changes following the EOF1, which means that over phase 4, 5, 6 (Maritime Continent) region, the MJO 362 frequency becomes less and over phase region 1, 7 and 8 (central Pacific and the western Indian Ocean) 363 MJO frequency becomes more. From the canonical eastern Pacific cold to warm ENSO phases, MJO 364 frequency anomaly changes following the EOF2 pattern which is associated with the increased MJO 365 frequency in the phase regions 2, 3, 4 (central and east Indian ocean) and decreased frequency over phase 366 regions 6, 7, 8 (west to the central Pacific Ocean). From a mathematical point of view, it can be stated that 367 MJO frequency EOFs are observed in MJO frequency data due to the basic MJO frequency state change 368 over the eight phase regions during the two types of ENSO.

369 We conducted the composite analyses of different atmospheric variables during CP and EP-type 370 ENSO phases to identify the reason behind MJO frequency spatial patterns. We find that the mean Walker 371 circulation changes during these two types of ENSO phases alter the mean moisture distribution over the 372 equatorial region. The change in the moisture distribution impacts the intraseasonal moist static energy 373 tendencies which restrict the MJO propagation over the different part of the warm pool introducing the 374 zonal asymmetry in MJO propagation.

375 Previous studies on the interannual variability of MJO frequency were mostly confined to studying 376 the MJO frequency during boreal or extended boreal winter seasons. On the contrary, the current study 377 investigates the MJO frequency for all seasons and tries to identify dominant spatial patterns of MJO 378 frequency which have prominent interannual variability. RMM index data for MJO is calculated from OLR 
379 and zonal wind by removing the ENSO signal from the data. We show that the intrinsic influences of ENSO

380 are still present in the RMM MJO frequency data that is separated from the ENSO signal.

\section{Methods}

\section{ENSO seasons}

383 We computed two type of ENSO indices during the period 1979 to 2018 from Niño 3 and Niño 4 indices 384 following Sullivan et al. ${ }^{25}$. Sullivan et al. ${ }^{25}$ derived EP and CP index from Niño 3 and Niño 4 indices using 385 the following formulas, $E P=$ Niño3_normalized $-0.5 *$ Niño4_normalized and $C P=$ 386 Niño4_normalized - $0.5 *$ Niño3_normalized. We prepared a seasonal EP and CP time series from 387 the monthly values for four separated seasons, i.e. boreal winter (December-January-February or DJF), 388 boreal spring (March-April-May or MAM), boreal summer (June-July-August or JJA) and boreal autumn 389 (September-October-November or SON). We chose these four seasons considering the evolution of El 390 Niño. El Niño generally evolves from its initial stage during boreal summer (JJA) to its most active stage 391 during boreal winter (DJF) and decays in following boreal spring (MAM). We identified the warm and cold

392 EP-type ENSO seasons when the seasonal time series of the EP index crossed its positive and negative 393 standard deviation values respectively (Supplementary Fig. 1). Thus from 1979 (DJF) to 2018 (SON), 394 positive, negative and neutral EP-type ENSO seasons were identified. Similarly, as EP-type ENSO seasons, 395 warm, cold and neutral phases of CP-type ENSO (El Niño Modoki) were identified based on CP index 396 (Supplementary Fig. 1 and Supplementary Table 1). We identified two types of ENSO phases to examine 397 their influence on MJO variability.

\section{MJO Frequency}

399 The interannual variability of the MJO is investigated in terms of the frequency of occurrence of the MJO 400 phases in boreal winter by numerous studies ${ }^{18,19,26}$. We have adopted the same definition for the frequency 401 of occurrence of MJO phases as in the earlier studies. For convenience, we have abbreviated the term 402 "frequency of occurrence of MJO phases" as MJO frequency in this study. MJO frequency represents the 403 number of MJO active days (with RMM amplitude greater than 1.0) over any particular phase locations in 404 a season. RMM amplitude greater than 1.0, conventionally represent the active MJO state ${ }^{20}$. We calculate 405 MJO frequency at eight RMM phase locations over the time period 1979 to 2018 for DJF, MAM, JJA and 406 SON seasons. From December 1979 to November 2018, MJO frequencies in 156 seasons are considered in 407 this study. For DJF, MAM, JJA and SON, the mean and standard deviation of MJO frequency over the 408 eight phase locations are represented in the Supplementary Fig. 2, where we can see the seasonality in MJO 409 frequency data. 
411 MJO frequency possesses seasonal characteristics which we discussed in the introduction section. We

412 removed the seasonality from the MJO frequency data by standardizing each specific season's data by that

413 particular season's climatology (e.g. MJO frequency in SON is standardized by SON climatology of MJO

414 frequency) and thus we obtained normalized MJO frequency anomaly data at each phase location (Fig. 1a).

415 This normalized MJO frequency anomaly is independent to seasonal characteristics of MJO which are

416 evident through more MJO frequencies in boreal winter and spring than in boreal summer and autumn. The

417 MJO frequency anomaly, therefore, represents the interannual variability of MJO frequency excluding the

418 seasonal cycle of the MJO.

419 The derived MJO frequency anomaly data is a multivariate dataset which has eight variables 420 representing eight $\mathrm{RMM}$ phase regions $(\mathrm{m}=8)$ and 156 cases $(\mathrm{n}=156)$ representing 156 seasons (Fig. 1a).

421 We performed multivariate Principal Component analysis (PCA) or Empirical Orthogonal Function 422 analysis (EOF) on this data to explore linearly correlated phase regions having similar interannual MJO 423 frequency variation. We obtain the spatial patterns of MJO frequency variation through PCA in terms of 424 spatial EOFs.

425 We further use the biplot technique to represent the PCA result in the two-dimensional leading 426 principal component plane. Biplot is not commonly used in the field of meteorology. We discussed the 427 details of PCA and the biplot technique in the following section. Each season was represented in biplot 428 plane according to scores (principal components) of the two EOFs. We further use the concept of data 429 ellipse to enclose the ENSO season points and to describe the statistics of MJO frequency during the ENSO 430 phases. The details of data ellipse are also described in the following section.

$431 \quad$ PCA

432 The basic idea of PCA is to rotate the reference axis of the variables towards the direction of maximum 433 variability in the data. The leading eigenvectors (Empirical orthogonal Functions-EOFs or loadings or 434 principal axis) point towards directions of maximum variability. Structure of the eigenvectors in terms of 435 variables (EOFs) represents the linear relationship between the variables in the direction of maximum 436 variability. The data represented only by dominant eigenvectors are the dimension reduced version of the 437 data explaining a percentage of total variability. The eigenvalues denote the proportion of variance 438 concerning total variance explained by corresponding eigenvectors. The criteria for degeneracy of 439 eigenvalues are discussed by North et al., ${ }^{22}$. 


\section{PCA Biplot}

441 In two-dimensional space of two leading principal axes, we used the biplot technique to describe the 442 covariance PCA result. The article Gabriel $^{27}$ is the original foundation of the biplot technique. Jolliffe ${ }^{24}$ 443 discussed the basic concepts of biplot. Using the biplot technique, Takahasi et al. ${ }^{28}$ described two types of

444 ENSO events. Ivanov and Evtimov ${ }^{29}$ used the biplot method on northern hemispheric monthly temperature 445 anomaly data and had explained different attributes of the technique.

446 Biplot is the most compressed geometrical representation of information from a data matrix, where 447 the attempt is to represent both observation and variables in a two-dimensional space. Covariance biplot 448 describes the covariance PCA outcome in two leading principal component space. Two-dimensional biplot 449 retains first two eigenvectors to give an approximate representation of the data. We will discuss three main 450 basic features of biplot which are its axes, arrows and points. Above mentioned studies explained the 451 detailed theoretical development of these features. The two axes in biplot represent the first two principal 452 axes (EOFs) normalized to unit length by corresponding eigenvalues or variances. The arrow vectors 453 describe the variables in two principal axes space. The length of an arrow represents the standard deviation 454 of the corresponding variable and cosine between two arrows represent the linear correlation between the 455 variables. The position vectors or points denotes the case entry in the centered data matrix. The position 456 vectors are the scoring values (Principal Components-PCs) corresponding to the first two eigenvectors 457 having normalized unit variance. The Euclidean distance between two points denotes the 'Mahalanobis 458 distance' between the cases. The 'Mahalanobis distance' explains the statistical similarity between the two 459 events. Two cases are statistically similar when they are closer to each other. Therefore, the similar events 460 having less 'Mahalanobis distance' form clusters in two-dimensional biplot. The limitations come in biplot 461 when the number of variables is high, and difficulty arises to distinguish between variable vectors. 462 However, biplot allows visual appraisal of the inherent structure of the data, its variance and covariance 463 structures, clustering of the events, extremes and multivariate outliers.

\section{Clusters and Data ellipse}

465 To represent the clusters of events in biplot space we used the data or concentration ellipse ${ }^{30}$. The data 466 ellipse represents a visual summary of a scatter plot indicating the means, standard deviations, correlation, 467 and the slope of the regression line for two variables ${ }^{31}$. Friendly et al. ${ }^{31}$ discussed the role of ellipsoids in 468 statistical data analysis and visualizations. For a bivariate normally distributed data $x=(x 1, x 2)$, 469 probability density function $\phi(x)$ is given by

$$
\phi(x)=1 / 2 \pi|\Sigma|^{-1 / 2} \exp \left\{-1 / 2(x-\mu)^{\prime} \Sigma^{-1}(x-\mu)\right\}, \quad \text { where } \quad \Sigma=\left(\sigma_{11} \sigma_{12} \sigma_{21} \sigma_{22}\right)
$$


471 Here $\Sigma$ is the covariance matrix of bivariate normal data $x$. The quadratic form in the exponent of the 472 equation is a statistical distance measure, often referred to as Mahalanobis distance. Mahalanobis distance 473 is the squared statistical distance of $x$ from $\mu$ accounting the fact that the variables may be correlated and 474 have different variances. The quadratic form in the exponent follows the $\chi^{2}$ distribution with two degrees 475 of freedom. Constant density contours of bivariate normally distributed data follow the equation of an 476 ellipse with $\varepsilon_{c}=(x-\mu)^{\prime} \Sigma^{-1}(x-\mu)=c^{2}$, where $\mathrm{c}$ is the size of the ellipse. The ellipse is generally 477 referred to as data or concentration ellipse. The data ellipse encloses the points having squared Mahalanobis 478 distance $D^{2}<=c 2=\chi^{2}(\alpha)$. One standard deviation data ellipse encloses $68 \%$ of the data with $c^{2}=$ $479 \chi^{2}(\alpha=0.32)=2.28$. Where 95\% data ellipse has $c^{2}=\chi^{2}(\alpha=0.05)=5.99$. The axes of the ellipse are 480 in the direction of the eigenvectors of the covariance matrix $\Sigma$ and the length of the axes are proportional

481 to $\sqrt{\lambda_{1}}$ and $\sqrt{\lambda_{2}}$. The orientation of the semi-major axis $\left(\lambda_{1}\right)$ of an ellipse with the reference axes depicts 482 the positive or negative correlation between the two normally distributed variables. The area of the data 483 ellipse containing the central $(1-\alpha) \times 100 \%$ of a bivariate normal data is $\pi c^{2} \sqrt{\sigma_{11} \sigma_{22}\left(1-\rho^{2}\right)}$. The 484 eccentricity of a data ellipse is high $\left(\lambda_{1}>\lambda_{2}\right)$ when there is a large variance in one variable $\left(\sigma_{11}>\sigma_{22}\right.$ or 485 opposite) or significant covariance existed $(\sigma 12)$ between two variables. A low eccentricity indicates 486 similar variances $\left(\sigma_{11} \approx \sigma_{22}\right)$ and less covariance (independent variables with $\sigma_{12} \approx 0$ ) among the 487 variables. For PCA, biplot and data ellipse, we have used two R library, "FactoMineR" and "factoextra"

\section{Intraseasonal parameters}

489 We applied a 20-100 days band-pass filter on daily OLR (a proxy of convection) to extract the intraseasonal 490 signal of OLR. We compute the seasonal mean of the filtered OLR anomaly for DJF, MAM, JJA, SON 491 seasons from 1979 to 2018 . We obtained the space time filtered (1-10 wavenumber and 20-100 days periodicity) CMAP daily precipitation data representing eastward propagating MJO signal ${ }^{33}$. We also computed the seasonal mean SST, omega $(\omega)$, specific humidity $(q)$ anomaly from the monthly datasets.

Maloney ${ }^{34}$ explained that the intra-seasonal moist static energy (MSE) budget could describe the eastward propagation of MJO. The recharge of column integrated MSE at intra-seasonal timescale occurs at the east of the MJO convection center with the help of low-level easterlies and mean background moisture field which helps MJO to propagate eastward. The discharge of column integrated MSE occurs during and after the precipitation occurs at MJO convection along with the lower level westerly anomalies, which stops MJO movement in the westward direction. Therefore, MSE tendency is positive at the east side of MJO convection center and negative at the west side (behind) it. With the help of the moist static energy and its tendency, we tried to explain the result in our study. We computed the moist static energy $\left(m=C_{p} T+\right.$ $L q+\varphi)$ from air temperature, specific humidity and geo-potential height dataset. Then, we obtained the 
503 intraseasonal (20-100 days filtered) moist static energy anomaly $\left(\mathrm{m}^{\prime}\right)$ and moist static energy tendency $<$

$504 d m^{\prime} / d t>$.

\section{Data availability}

506 The present study is based on 1979 to 2018 period, corresponding to the availability of OLR and the RMM

507 index in the satellite era 5 . RMM index data from 1979 to 2018 is obtained from the Australian Bureau of

508 Meteorology. Monthly Niño 3 and Niño 4 indices are calculated from Extended Reconstructed Sea Surface

509 Temperature version 5 (ERSSTv5) dataset with $2^{\circ} \times 2^{\circ}$ resolution ${ }^{35}$. These indices are used to identify the

510 warm and cold Eastern Pacific (EP)-type and central Pacific (CP)-type ENSO phases ${ }^{23,36}$.

511 We used daily NOAA interpolated OLR data with $2.5^{\circ} \times 2.5^{\circ}$ resolution in our present study ${ }^{37}$. We 512 obtained the $2.5^{\circ} \times 2.5^{\circ}$ pentad CPC Merged Analysis of Precipitation (CMAP) data and interpolated the

513 data to daily ${ }^{38}$. We used the zonal wind (u), meridional wind (v), omega ( $\omega$ ), specific humidity (q), air

514 temperature $(\mathrm{T})$ and geopotential height ( $\varphi$ from NCEP/NCAR reanalysis 1 dataset ${ }^{39}$. We also used monthly

515 Hadley Centre Sea Ice and Sea Surface Temperature data set (HadISST) to check the consistency of our 516 results $^{40}$.

\section{References}

518 1. Madden, R. A. \& Julian, P. R. Detection of a 40-50 Day Oscillation in the Zonal Wind in the

519 Tropical Pacific. J. Atmos. Sci. 28, 702-708 (1971).

520 2. Madden, R. A. \& Julian, P. R. Description of Global-Scale Circulation Cells in the Tropics with a

521 40-50 Day Period. J. Atmos. Sci. 29, 1109-1123 (1972).

522 3. Lau, W. K.-M. \& Waliser, D. E. Intraseasonal variability in the atmosphere-ocean climate system.

523 (Springer Science \& Business Media, 2011).

524 4. Zhang, C. Madden-Julian Oscillation: Bridging Weather and Climate. Bull. Amer. Meteor. Soc. 94, $525 \quad$ 1849-1870 (2013).

526 5. Wheeler, M. C. \& Hendon, H. H. An all-season real-time multivariate MJO index: Development of 527 an index for monitoring and prediction. Monthly Weather Review 132, 1917-1932 (2004).

528 6. Salby, M. L. \& Hendon, H. H. Intraseasonal behavior of clouds, temperature, and motion in the 529 Tropics. Journal of the Atmospheric Sciences 51, 2207-2224 (1994). 
530 7. Lu, W. \& Hsu, P.-C. Factors controlling the seasonality of the Madden-Julian Oscillation. Dynamics $531 \quad$ of Atmospheres and Oceans 78, 106-120 (2017).

532 8. Konda, G. \& Vissa, N. K. Intraseasonal Convection and Air-Sea Fluxes Over the Indian Monsoon 533 Region Revealed from the Bimodal ISO Index. Pure and Applied Geophysics 1-16.

534 9. Wu, M.-L. C., Schubert, S. D., Suarez, M. J., Pegion, P. J. \& Waliser, D. E. Seasonality and 535 meridional propagation of the MJO. Journal of climate 19, 1901-1921 (2006).

536 10. Hendon, H. H., Zhang, C. \& Glick, J. D. Interannual variation of the Madden-Julian oscillation 537 during austral summer. Journal of Climate 12, 2538-2550 (1999).

538 11. Slingo, J., Rowell, D., Sperber, K. \& Nortley, F. On the predictability of the interannual behaviour of 539 the Madden-Julian Oscillation and its relationship with El Niño. Quarterly Journal of the Royal $540 \quad$ Meteorological Society 125, 583-609 (1999).

541 12. Deng, L., Li, T., Liu, J. \& Peng, M. Factors controlling the interannual variations of MJO intensity. $542 \quad$ Journal of Meteorological Research 30, 328-340 (2016).

543 13. Moon, J.-Y., Wang, B. \& Ha, K.-J. ENSO regulation of MJO teleconnection. Climate dynamics 37, $544 \quad 1133-1149(2011)$.

545 14. Hendon, H. H., Wheeler, M. C. \& Zhang, C. Seasonal dependence of the MJO-ENSO relationship.

$546 \quad$ Journal of Climate 20, 531-543 (2007).

547 15. Pang, B., Chen, Z., Wen, Z. \& Lu, R. Impacts of two types of El Niño on the MJO during boreal

$548 \quad$ winter. Advances in Atmospheric Sciences 33, 979-986 (2016).

549 16. Zhang, C. \& Zhang, B. QBO-MJO Connection. Journal of Geophysical Research: Atmospheres 123, $550 \quad 2957-2967$ (2018).

551 17. Lin, H., Brunet, G. \& Yu, B. Interannual variability of the Madden-Julian Oscillation and its impact 552 on the North Atlantic Oscillation in the boreal winter. Geophysical Research Letters 42, 5571-5576 553 (2015). 
554 18. Yoo, C., Feldstein, S. \& Lee, S. The impact of the Madden-Julian Oscillation trend on the Arctic 555 amplification of surface air temperature during the 1979-2008 boreal winter. Geophysical Research $556 \quad$ Letters 38, (2011).

557 19. Lin, H., Brunet, G. \& Yu, B. Interannual variability of the Madden-Julian Oscillation and its impact 558 on the North Atlantic Oscillation in the boreal winter. Geophysical Research Letters 42, 5571-5576 $559 \quad$ (2015).

560 20. Roxy, M. K. et al. Twofold expansion of the Indo-Pacific warm pool warps the MJO life cycle.

$561 \quad$ Nature 575, 647-651 (2019).

562 21. Dasgupta, P., Metya, A., Naidu, C. V., Singh, M. \& Roxy, M. K. Exploring the long-term changes in 563 the Madden Julian Oscillation using machine learning. Scientific Reports 10, 18567 (2020).

564 22. North, G. R., Bell, T. L., Cahalan, R. F. \& Moeng, F. J. Sampling errors in the estimation of 565 empirical orthogonal functions. Monthly Weather Review 110, 699-706 (1982).

566 23. Ashok, K., Behera, S. K., Rao, S. A., Weng, H. \& Yamagata, T. El Niño Modoki and its possible 567 teleconnection. Journal of Geophysical Research: Oceans 112, (2007).

568 24. Jolliffe, I. T. Graphical representation of data using principal components. Principal component $569 \quad$ analysis 78-110 (2002).

570 25. Sullivan, A. et al. Robust contribution of decadal anomalies to the frequency of central-Pacific El $571 \quad$ Niño. Scientific Reports 6, 38540 (2016).

572 26. Wang, F., Tian, W., Xie, F., Zhang, J. \& Han, Y. Effect of Madden-Julian Oscillation Occurrence 573 Frequency on the Interannual Variability of Northern Hemisphere Stratospheric Wave Activity in $574 \quad$ Winter. J. Climate 31, 5031-5049 (2018).

575 27. Gabriel, K. R. The biplot graphic display of matrices with application to principal component $576 \quad$ analysis. Biometrika 58, 453-467 (1971).

577 28. Takahashi, K., Montecinos, A., Goubanova, K. \& Dewitte, B. ENSO regimes: Reinterpreting the $578 \quad$ canonical and Modoki El Niño. Geophysical Research Letters 38, (2011). 
579 29. Ivanov, M. A. \& Evtimov, S. N. Seasonality in the biplot of Northern Hemisphere temperature 580 anomalies. Quarterly Journal of the Royal Meteorological Society 140, 2650-2657 (2014).

581 30. Friendly, M. \& Sigal, M. Recent advances in visualizing multivariate linear models. Revista $582 \quad$ Colombiana de Estadistica 37, 261-283 (2014).

583 31. Friendly, M., Monette, G., Fox, J. \& others. Elliptical insights: understanding statistical methods 584 through elliptical geometry. Statistical Science 28, 1-39 (2013).

585 32. Kassambara, A. Practical Guide To Principal Component Methods in R: PCA, M (CA), FAMD, 586 MFA, HCPC, factoextra. vol. 2 (STHDA, 2017).

587 33. Kiladis, G. N., Straub, K. H. \& Haertel, P. T. Zonal and Vertical Structure of the Madden-Julian 588 Oscillation. J. Atmos. Sci. 62, 2790-2809 (2005).

589 34. Maloney, E. D. The Moist Static Energy Budget of a Composite Tropical Intraseasonal Oscillation in 590 a Climate Model. J. Climate 22, 711-729 (2009).

591 35. Huang, B. et al. Extended Reconstructed Sea Surface Temperature, Version 5 (ERSSTv5): Upgrades, 592 Validations, and Intercomparisons. J. Climate 30, 8179-8205 (2017).

593 36. Jadhav, J., Panickal, S., Marathe, S. \& Ashok, K. On the possible cause of distinct El Niño types in 594 the recent decades. Scientific reports 5, 17009 (2015).

595 37. Liebmann, B. \& Smith, C. A. Description of a complete (interpolated) outgoing longwave radiation 596 dataset. Bulletin of the American Meteorological Society 77, 1275-1277 (1996).

597 38. Xie, P. \& Arkin, P. A. Global precipitation: A 17-year monthly analysis based on gauge observations, 598 satellite estimates, and numerical model outputs. Bulletin of the American Meteorological Society 78, $599 \quad 2539-2558(1997)$.

600 39. Kalnay, E. et al. The NCEP/NCAR 40-Year Reanalysis Project. Bull. Amer. Meteor. Soc. 77, 437$601472(1996)$.

602 40. Rayner, N. et al. Global analyses of sea surface temperature, sea ice, and night marine air temperature 603 since the late nineteenth century. Journal of Geophysical Research: Atmospheres 108, (2003). 


\section{Acknowledgments}

606 P.D. acknowledges Dr. Michael J. McPhaden and Dr. Chidong Zhang from National Oceanic and 607 Atmospheric Administration (NOAA), Seattle for their valuable suggestions.

608

\section{Author contributions}

610 P.D. conceived the study, performed the analysis, and prepared the manuscript. R.M.K. provided the idea 611 and supervised the study. R.C. and C.V.N. gave valuable suggestions in manuscript preparation. A.M. 612 provided useful advice in the study.

613

614 Competing interests

615 The authors declare no competing interests.

616

617 

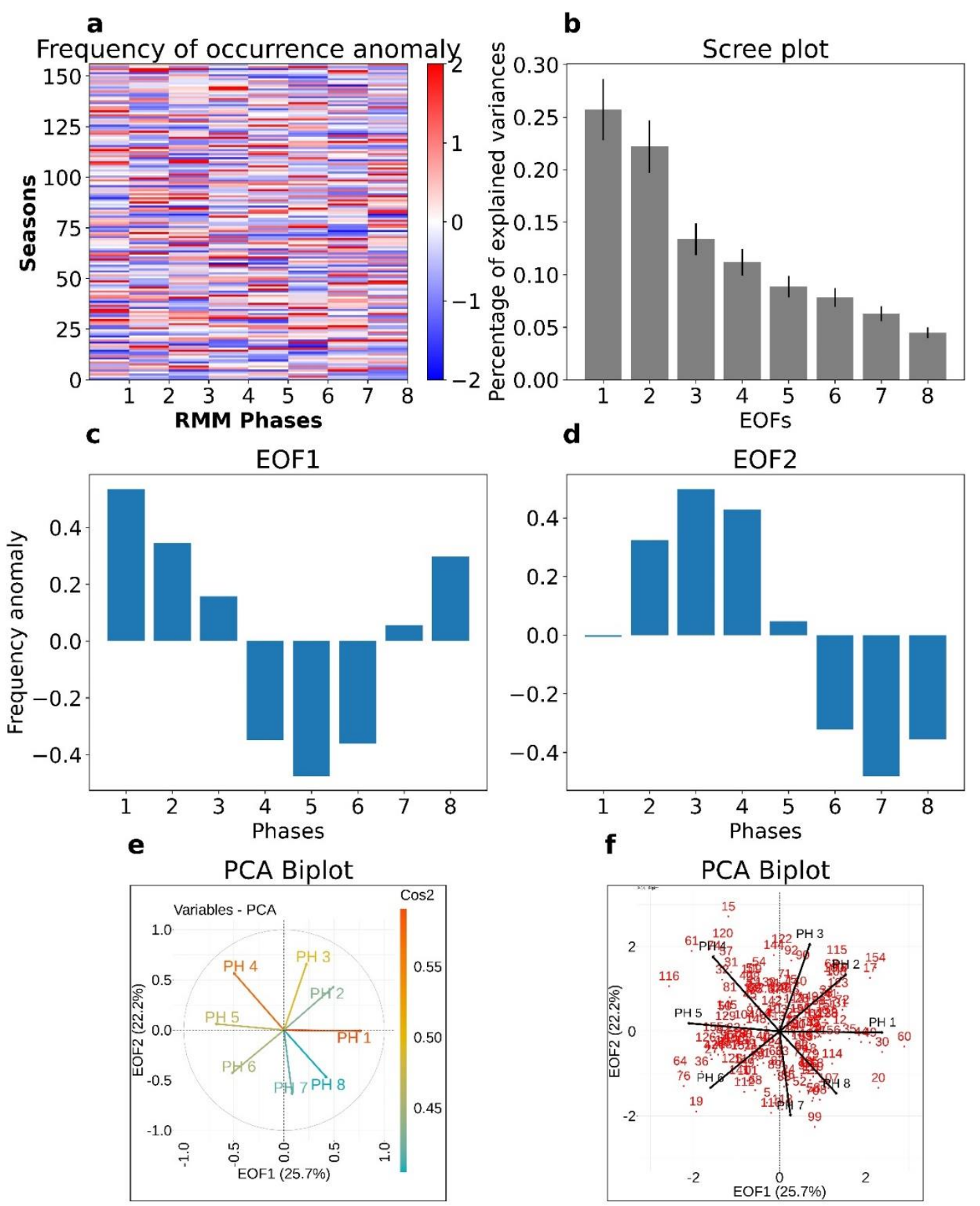

619 Figure 1. (a) MJO frequency anomaly (seasonally normalized) at eight RMM MJO phase locations 620 (days), (b) Scree plot denoting the percentage of variance contributed by the eight eigenvectors. The error 621 bars indicate the North et al. ${ }^{22}$ criteria for the EOFs. (c) and (d) First two leading spatial EOFs of MJO 622 frequency variability (days). (e) and (f) PCA-Biplot is denoting the relationship among the MJO 623 frequencies at the eight RMM phase locations. The color scale in (e) implies the cos2 (percentage of 624 variance explained through PC space) of the MJO frequency vector. The scatter points in (f) represent each 625 season from 1979 to 2018 over the PC plane. 

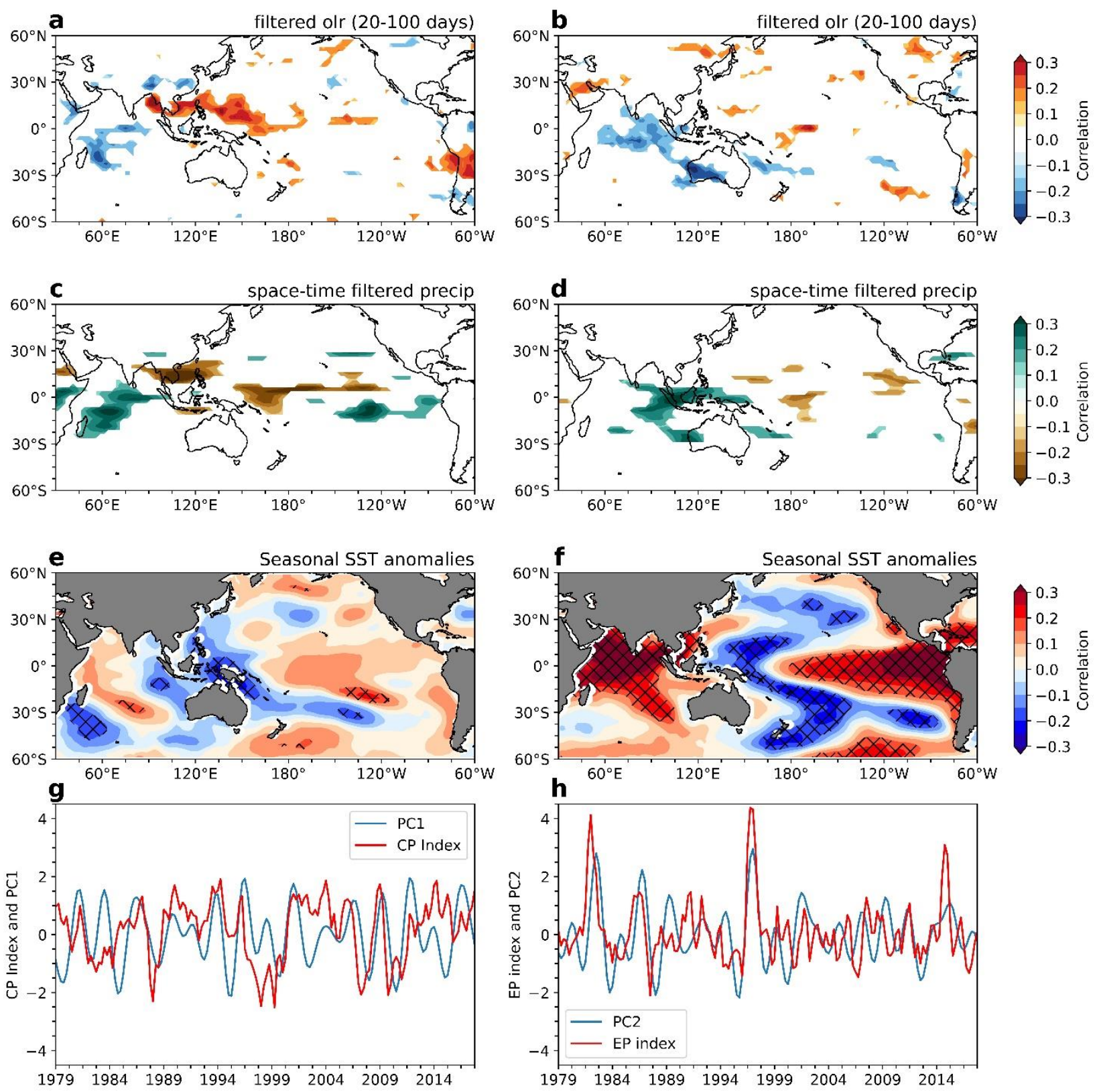

627 Figure 2. (a) and (b) MJO frequency EOF1 and EOF2 related 20-100 days filtered seasonal mean OLR 628 (W/m²) anomaly. Similarly, (c) and (d). represent 20-100 days and wavenumber 1-10 space-time filtered 629 precipitation anomaly ( $\mathrm{mm} /$ day). Only the correlation values exceeding $90 \%$ confidence level based on the 630 Student's t test are represented. (e) and (f). represent seasonal mean SST anomalies related to EOF1 and 631 EOF2 (hatched denote the locations having significant correlation with $90 \%$ confidence level). (g) 632 represents PC1 timeseries (2-8 years bandpass filtered) (blue line) and CP El Niño index (red line). (h) 633 shows PC2 timeseries (2-8 years bandpass filtered) (black line) and EP El Niño index (red line). 


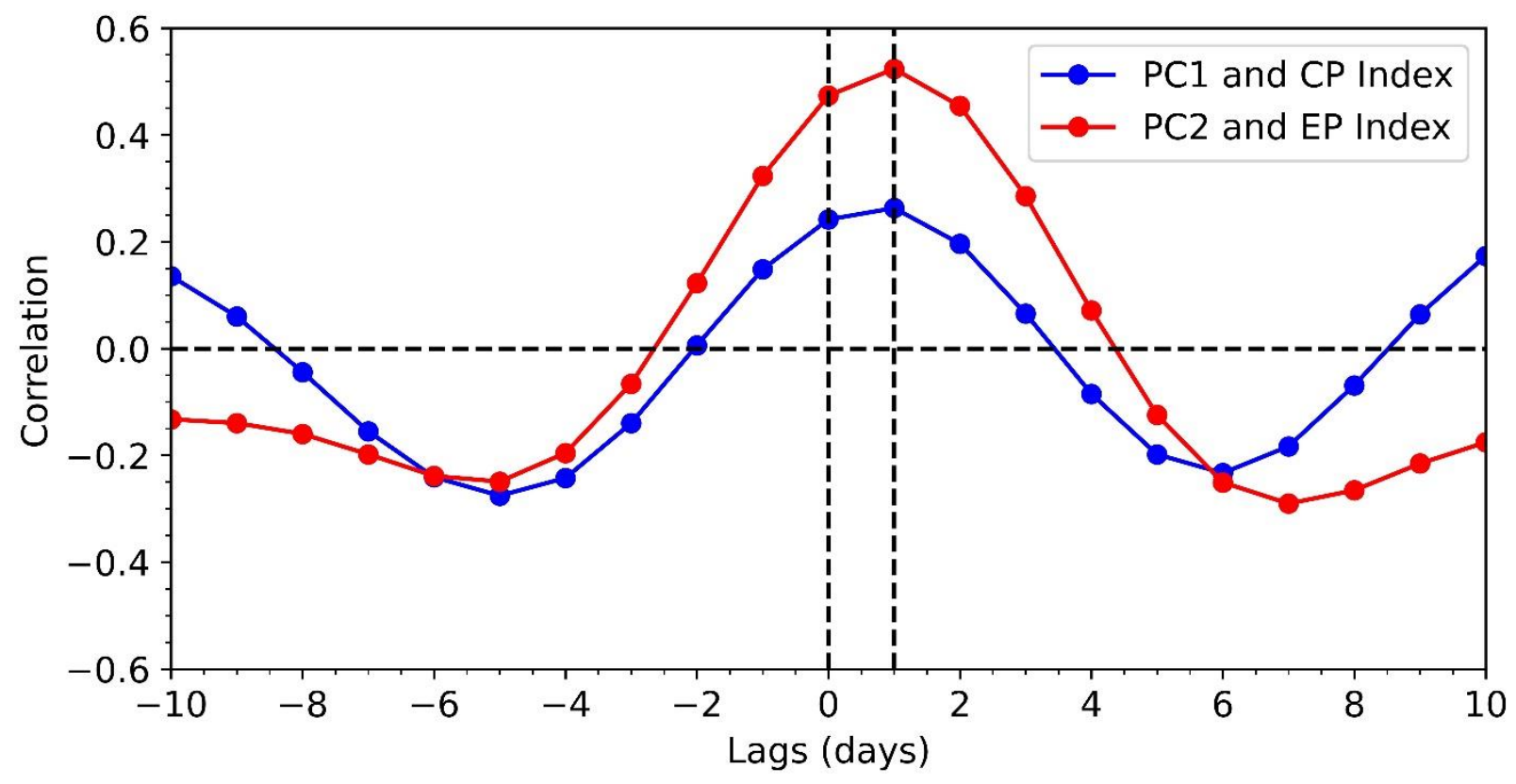

634

635 Figure 3. Lead-lag relationship between PC1 timeseries (2-8 years bandpass filtered) and CP El Niño index 636 (blue line). It is observed that negative CP El Niño leads PC1 timeseries by one season with correlation 637 value 0.27 . At lag 0 correlation is approximately 0.24 . Lead-lag relationship between PC2 time series (2-8 638 years bandpass filtered) and EP El index (blue line). EP El index leads PC2 timeseries by one season with 639 correlation value 0.523 . At lag 0 correlation is approximately 0.47 . 

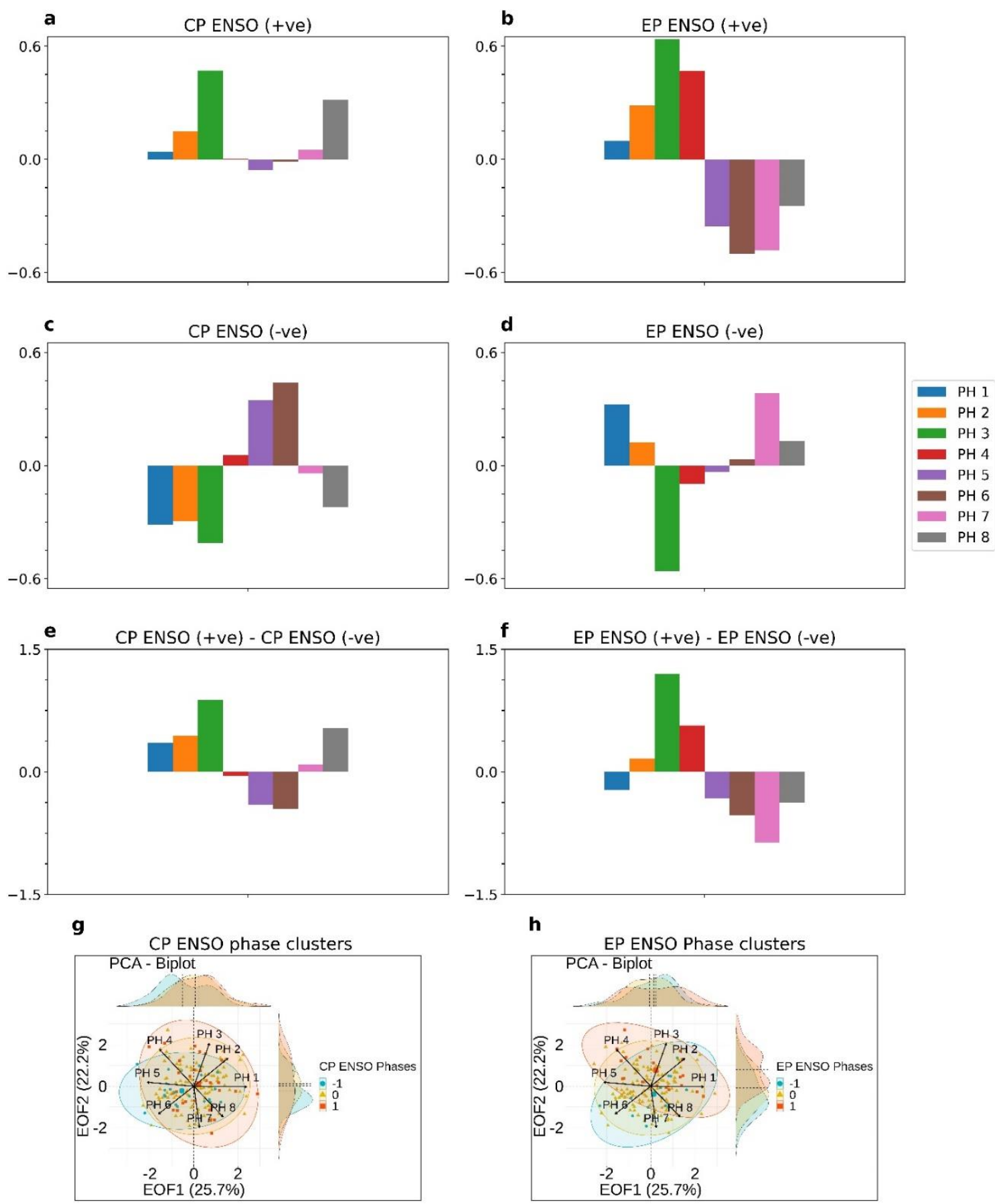

Figure 4. Composites of MJO frequency anomalies (standardized) at $8 \mathrm{RMM}$ phase regions during (a)

642 Positive CP-type ENSO seasons, (c) Negative CP-type ENSO seasons and their differences (e). Similarly, 643 composites for (b) Positive EP-type ENSO seasons, (d) Negative EP-type ENSO seasons and their 644 differences (f). (g) PCA biplot and clusters of positive (red), negative (blue) and neutral (yellow) CP-type 645 ENSO seasons. Data ellipses represent the statistics of different classes. (h) Similar as Fig. (g) for positive, 646 negative and neutral EP-type ENSO phases 

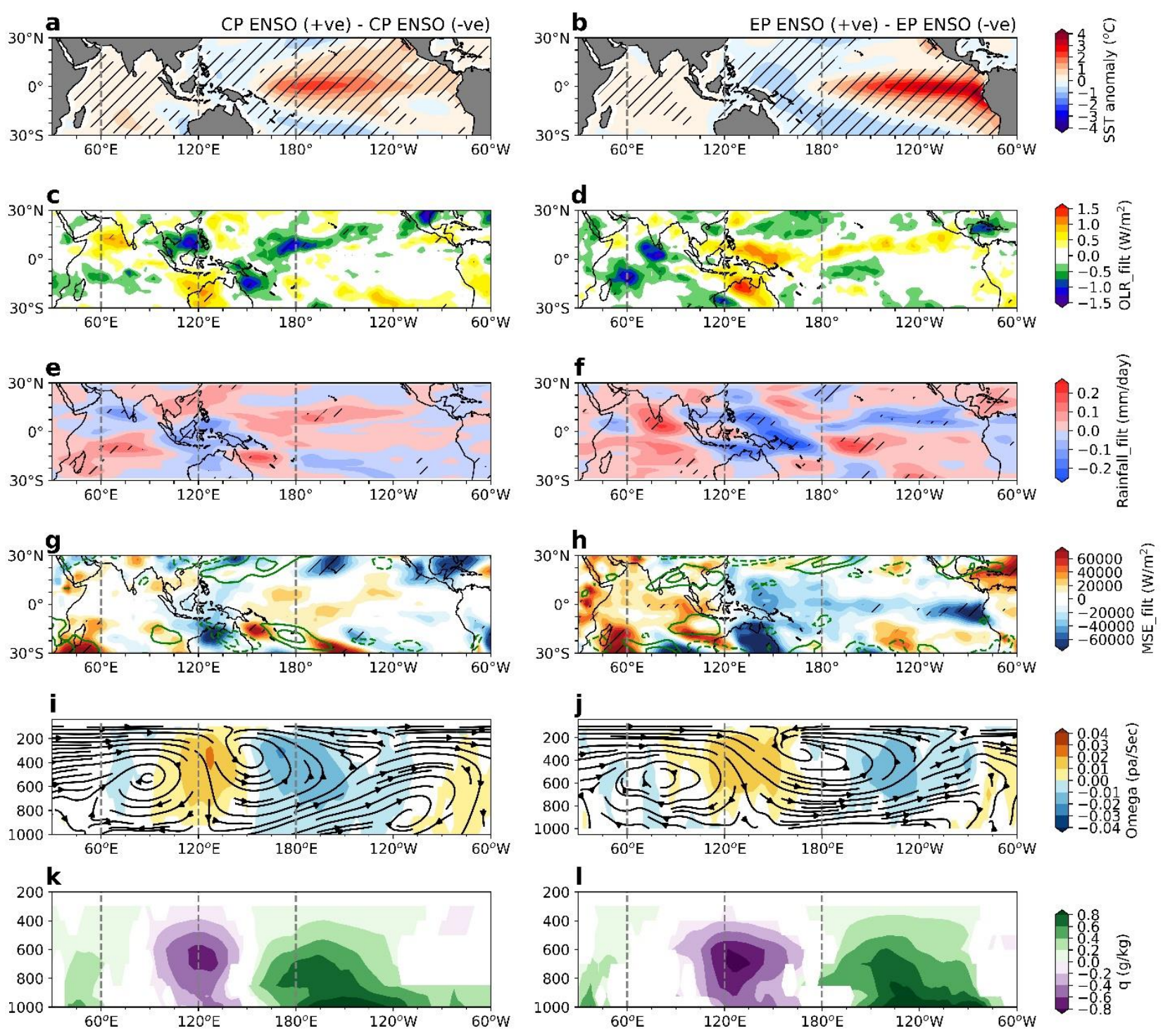

648 Figure 5. Composite differences of different fields between positive and negative CP-type and EP-type 649 ENSO phases. (a), (c), (e), (g), (i) and (k) represent the composite differences of SST, 20-100 days filtered 650 OLR, space-time filtered precipitation, 20-100 days filtered vertically integrated moist static energy 651 anomaly $\left\langle m^{\prime}>\right.$ and moist static energy tendency $\left\langle d m^{\prime} / d t>\right.$, omega and specific humidity respectively. 652 Similarly, (b), (d), (f), (h), (j) and (l) represent the composite differences of specified fields between 653 positive and negative EP-type ENSO seasons. Hatches represents the 90\% confidence level. In (i), (j), (k), 654 (l) only anomalies exceeding 90\% confidence level are plotted. 


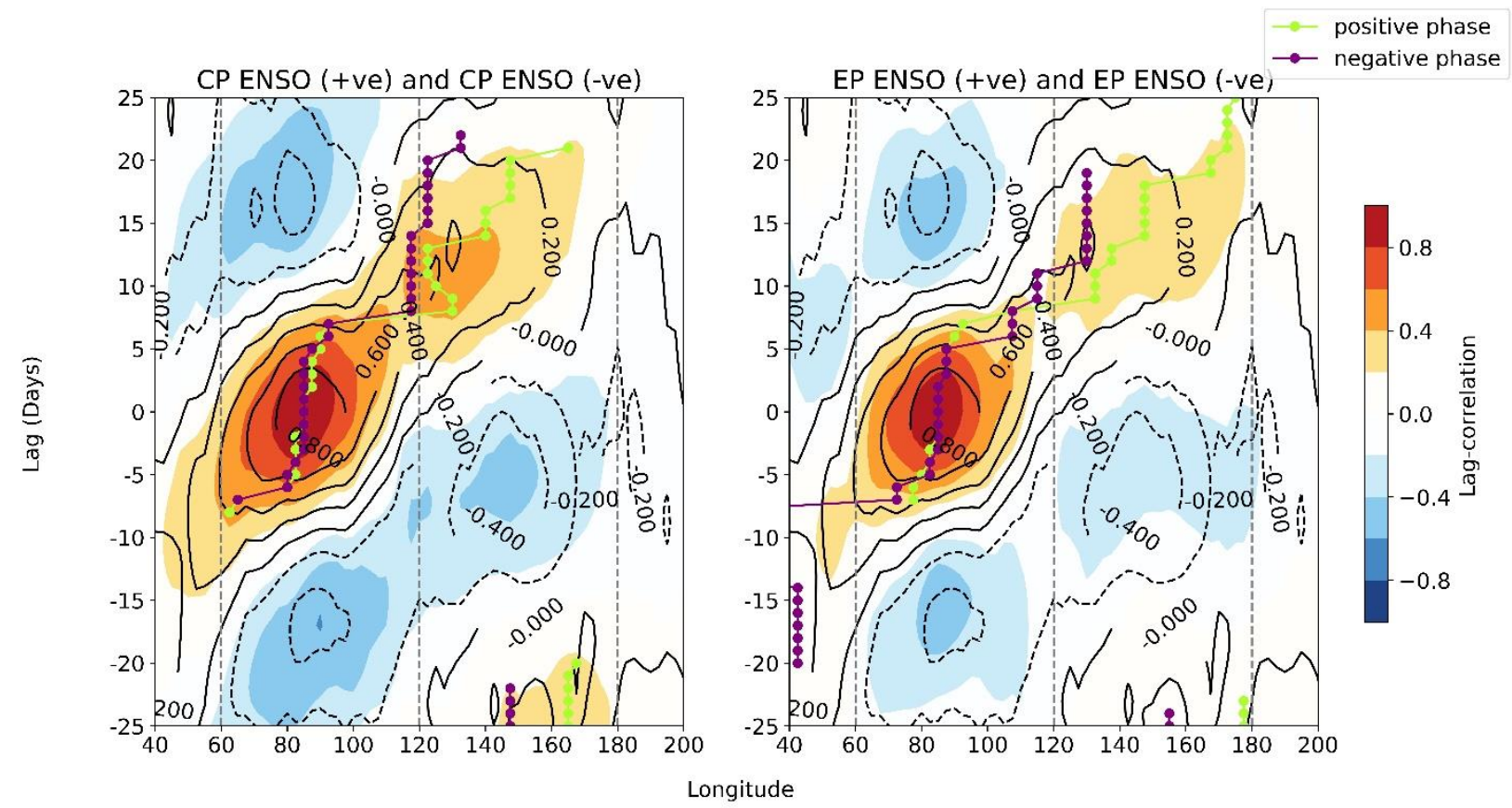

657 Figure 6. Lag propagation of 20-100 days filtered OLR with respect to central Indian Ocean $\left(80^{\circ} \mathrm{E}-90^{\circ} \mathrm{E}\right.$,

$\left.65815^{\circ} \mathrm{S}-15^{\circ} \mathrm{N}\right)$. Left panel shows the MJO propagation during positive and negative CP-type ENSO phases.

659 The shade represents the positive phase and contour denotes the negative CP-type ENSO phase. The dotted

660 lines represent the location (longitude) of maximum correlation at each time lag. The green and violet

661 represent the positive and negative phases. The right panel shows the propagation for EP ENSO positive 662 and negative phases.

663 Table 1: Correlation coefficients and $\cos 2$ of PCs and variables.

\begin{tabular}{|c|c|c|c|c|c|c|c|c|}
\hline Correlation & PH1 & PH2 & PH3 & PH4 & PH5 & PH6 & PH7 & PH8 \\
\hline PC1 & 0.76 & 0.50 & 0.22 & -0.49 & -0.68 & -0.51 & 0.08 & 0.42 \\
\hline PC2 & -0.01 & 0.43 & 0.66 & 0.56 & 0.06 & -0.42 & -0.64 & -0.47 \\
\hline Cos2 & \multicolumn{7}{|l|}{} \\
\hline PC1 & 0.59 & 0.24 & 0.05 & 0.24 & 0.46 & 0.26 & 0.01 & 0.18 \\
\hline PC2 & 0.00 & 0.18 & 0.44 & 0.32 & 0.00 & 0.18 & 0.41 & 0.22 \\
\hline
\end{tabular}


666 Table 2: Mean, standard deviation of normalized PC1 and PC2 in different ENSO classes

\begin{tabular}{|c|c|c|c|c|}
\hline Variables & \multicolumn{2}{|c|}{ EOF1 (PC1) } & \multicolumn{2}{c|}{ EOF2 (PC2) } \\
\hline & mean & STD & mean & STD \\
\hline EP- El Niño & 0.23 & 1.18 & 0.80 & 0.88 \\
\hline EP- La Niña & 0.15 & 0.96 & -0.40 & 0.92 \\
\hline CP- El Niño & 0.20 & 0.98 & 0.11 & 1.21 \\
\hline CP- La Niña & -0.52 & 1.00 & -0.22 & 0.72 \\
\hline
\end{tabular}




\section{Figures}
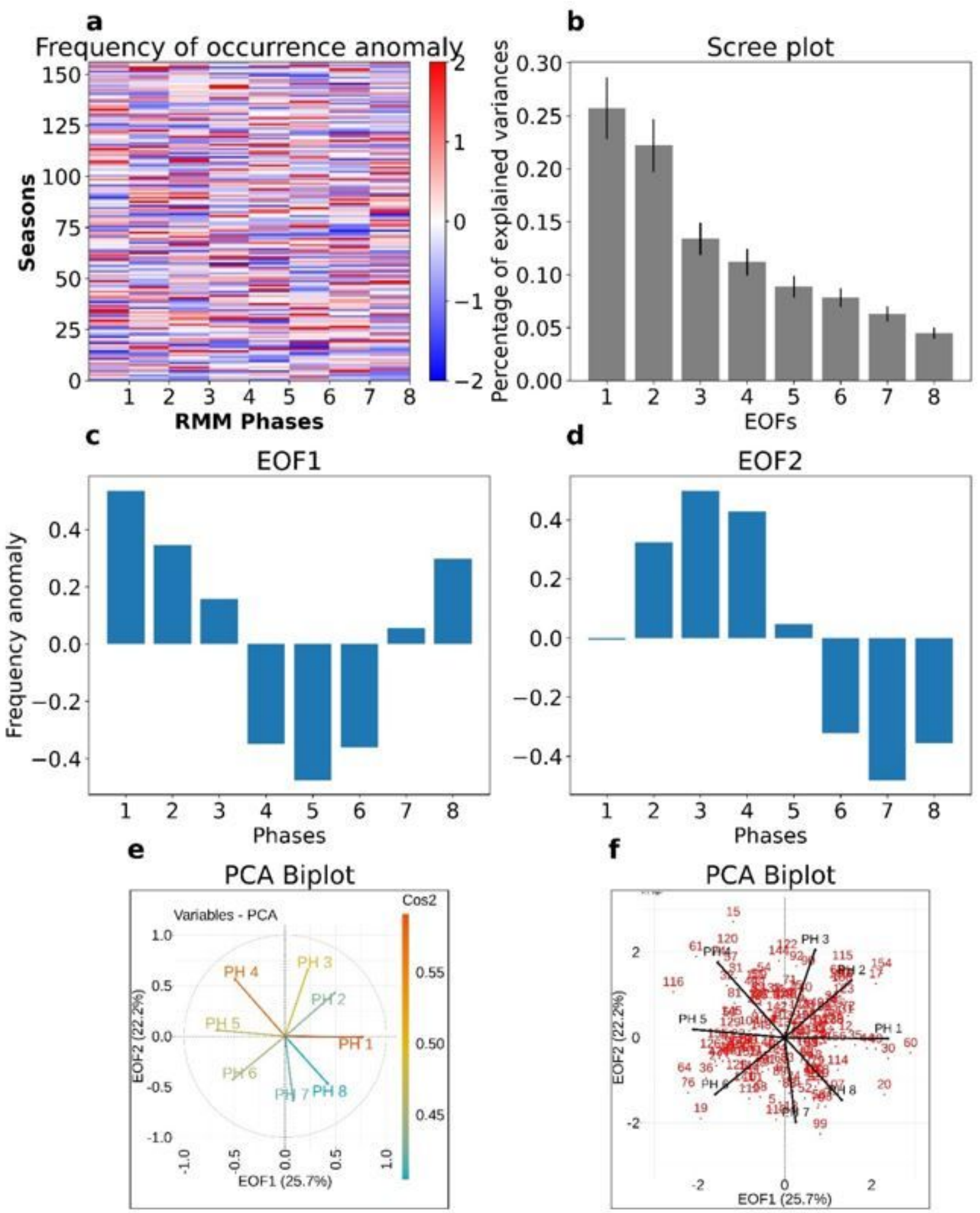

\section{Figure 1}

(a) MJO frequency anomaly (seasonally normalized) at eight RMM MJO phase locations (days), (b) Scree plot denoting the percentage of variance contributed by the eight eigenvectors. The error bars indicate the North et al. 22 criteria for the EOFs. (c) and (d) First two leading spatial EOFs of MJO 
frequency variability (days). (e) and (f) PCA-Biplot is denoting the relationship among the MJO frequencies at the eight RMM phase locations. The color scale in (e) implies the cos2 (percentage of variance explained through PC space) of the MJO frequency vector. The scatter points in (f) represent each season from 1979 to 2018 over the PC plane.
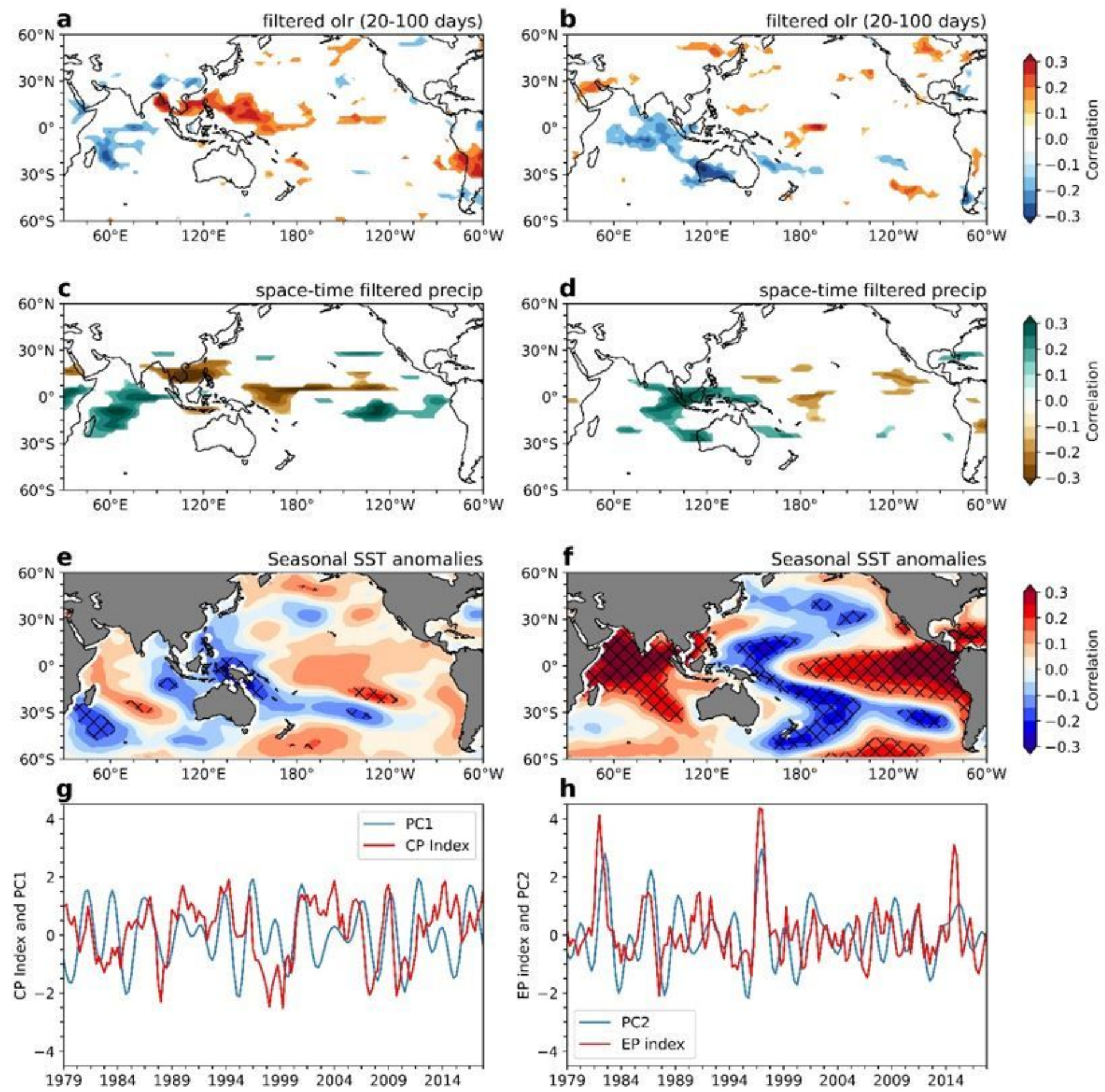

Figure 2

(a) and (b) MJO frequency EOF1 and EOF2 related 20-100 days filtered seasonal mean OLR $(\mathrm{W} / \mathrm{m} 2)$ anomaly. Similarly, (c) and (d). represent 20-100 days and wavenumber 1-10 space-time filtered 
precipitation anomaly ( $\mathrm{mm} /$ day). Only the correlation values exceeding $90 \%$ confidence level based on the Student's t test are represented. (e) and (f). represent seasonal mean SST anomalies related to EOF1 and EOF2 (hatched denote the locations having significant correlation with $90 \%$ confidence level). (g) represents PC1 timeseries (2-8 years bandpass filtered) (blue line) and CP El Niño index (red line). (h) shows PC2 timeseries (2-8 years bandpass filtered) (black line) and EP EI Niño index (red line). Note: The designations employed and the presentation of the material on this map do not imply the expression of any opinion whatsoever on the part of Research Square concerning the legal status of any country, territory, city or area or of its authorities, or concerning the delimitation of its frontiers or boundaries. This map has been provided by the authors.

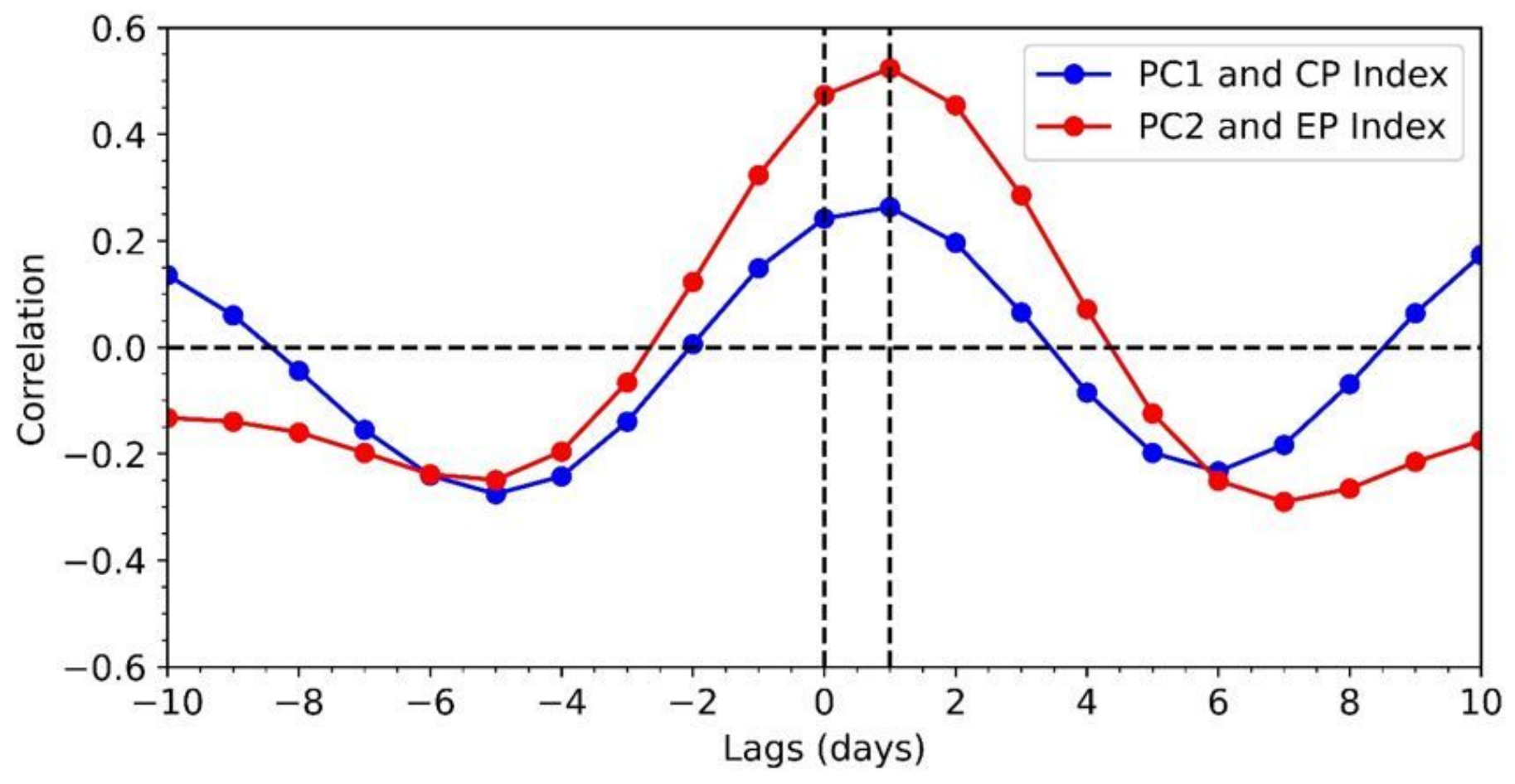

Figure 3

Lead-lag relationship between PC1 timeseries (2-8 years bandpass filtered) and CP El Niño index (blue line). It is observed that negative CP El Niño leads PC1 timeseries by one season with correlation value 0.27 . At lag 0 correlation is approximately 0.24 . Lead-lag relationship between PC2 time series (2-8 years bandpass filtered) and EP El index (blue line). EP El index leads PC2 timeseries by one season with correlation value 0.523 . At lag 0 correlation is approximately 0.47 . 

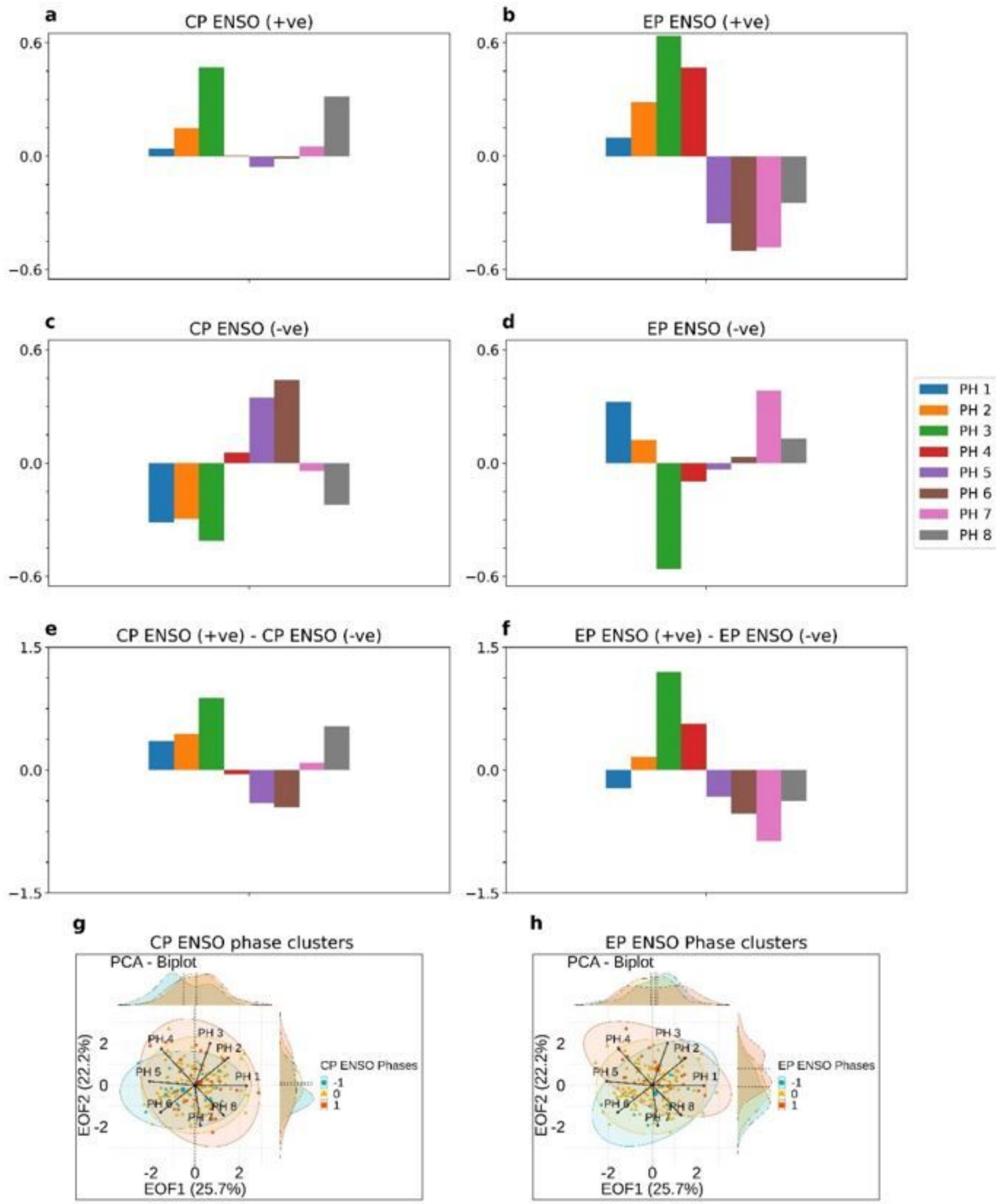

\section{Figure 4}

Composites of MJO frequency anomalies (standardized) at 8 RMM phase regions during (a) Positive CPtype ENSO seasons, (c) Negative CP-type ENSO seasons and their differences (e). Similarly, composites for (b) Positive EP-type ENSO seasons, (d) Negative EP-type ENSO seasons and their differences (f). (g) PCA biplot and clusters of positive (red), negative (blue) and neutral (yellow) CP-type ENSO seasons. 
Data ellipses represent the statistics of different classes. (h) Similar as Fig. (g) for positive, negative and neutral EP-type ENSO phases
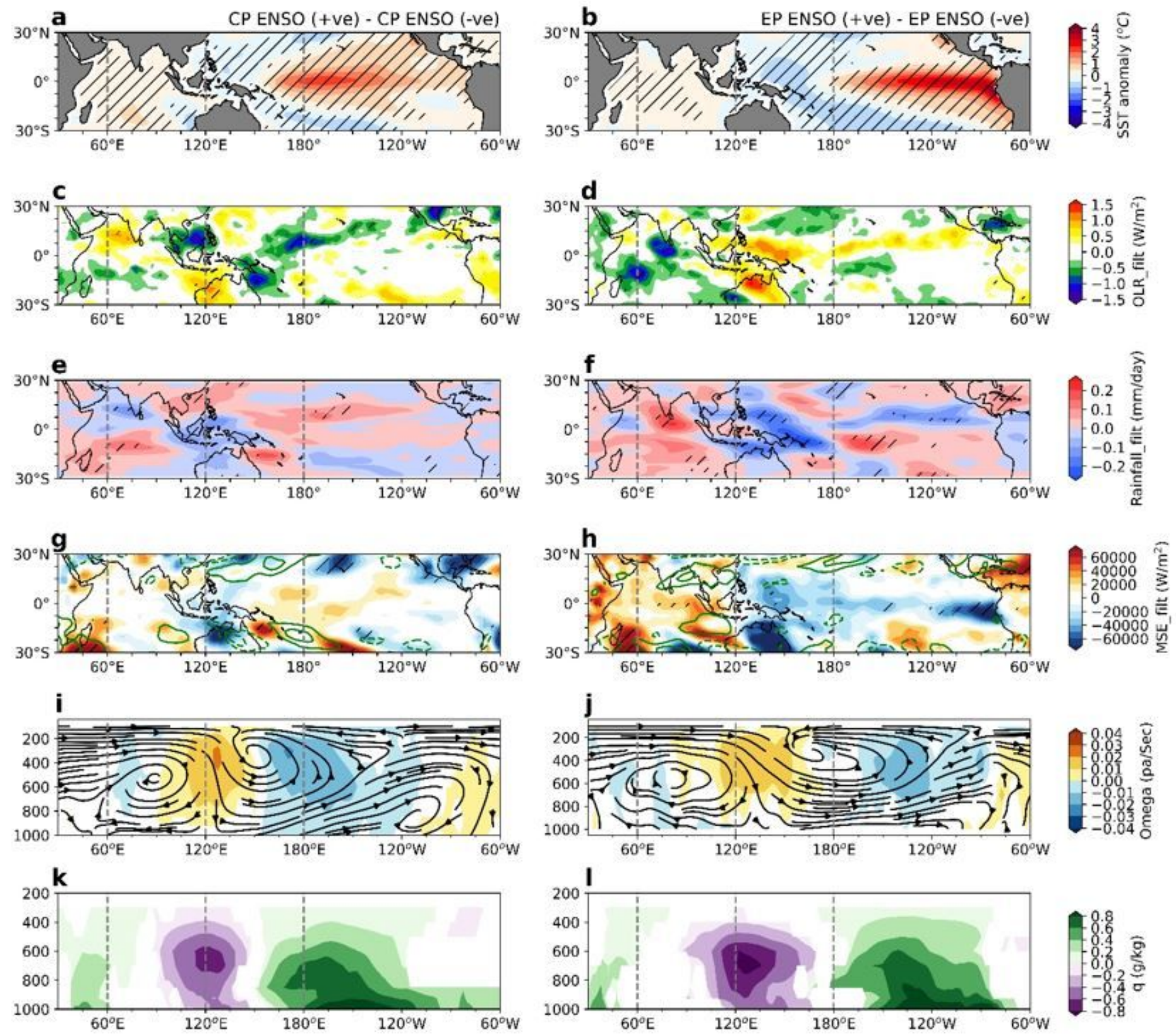

\section{Figure 5}

Composite differences of different fields between positive and negative CP-type and EP-type ENSO phases. (a), (c), (e), (g), (i) and (k) represent the composite differences of SST, 20-100 days filtered OLR, space-time filtered precipitation, 20-100 days filtered vertically integrated moist static energy anomaly $<\mathrm{m}^{\prime}>$ and moist static energy tendency $<\mathrm{dm} / \mathrm{dt}>$, omega and specific humidity respectively. Similarly, (b), (d), (f), (h), (j) and (I) represent the composite differences of specified fields between positive and negative EP-type ENSO seasons. Hatches represents the $90 \%$ confidence level. In (i), (j), (k), (l) only anomalies exceeding $90 \%$ confidence level are plotted. Note: The designations employed and the 
presentation of the material on this map do not imply the expression of any opinion whatsoever on the part of Research Square concerning the legal status of any country, territory, city or area or of its authorities, or concerning the delimitation of its frontiers or boundaries. This map has been provided by the authors.

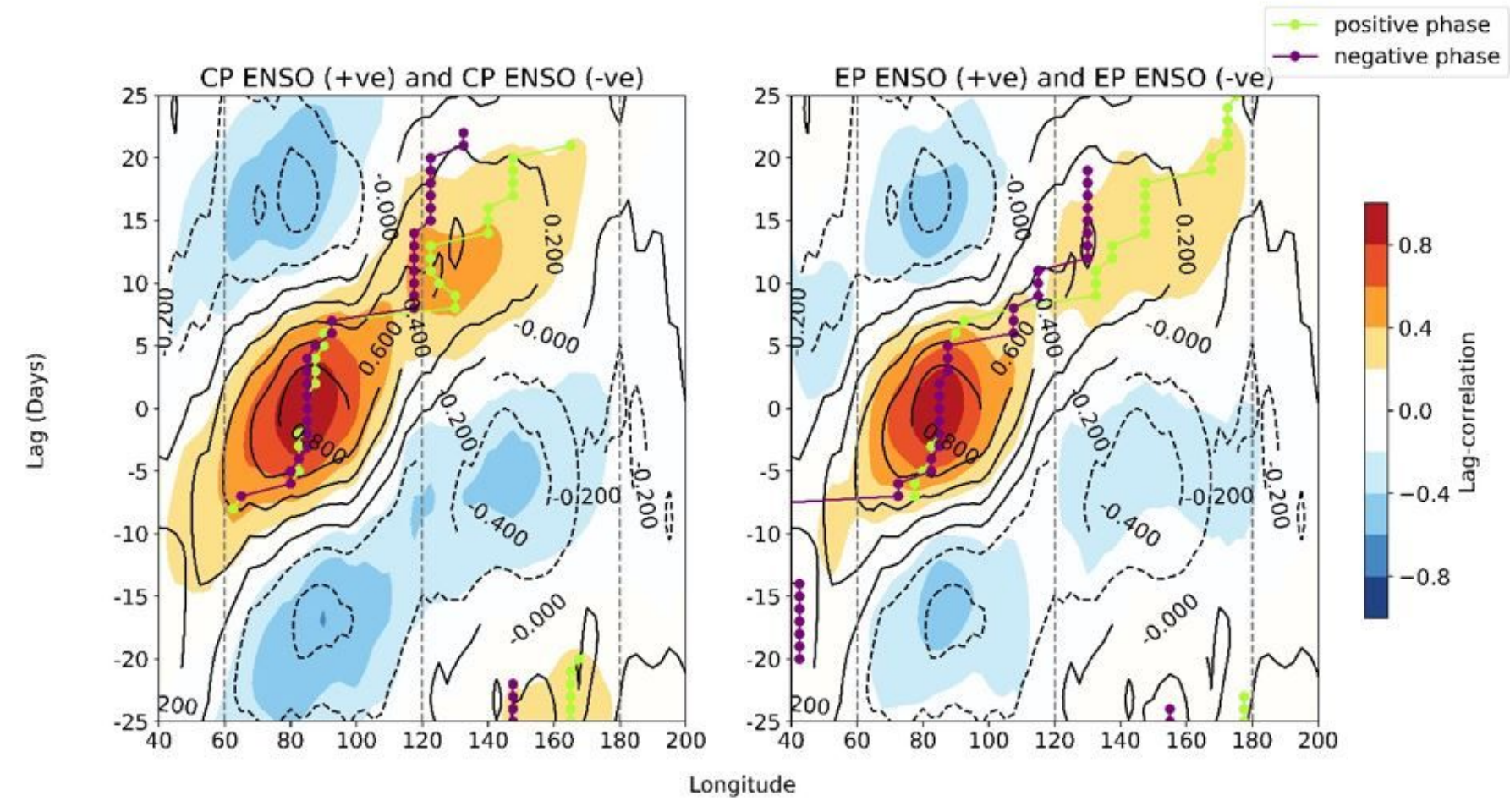

Figure 6

Lag propagation of $20-100$ days filtered OLR with respect to central Indian Ocean $\left(80^{\circ} \mathrm{E}-90^{\circ} \mathrm{E}, 15^{\circ} \mathrm{S}-15^{\circ} \mathrm{N}\right)$. Left panel shows the MJO propagation during positive and negative CP-type ENSO phases. The shade represents the positive phase and contour denotes the negative CP-type ENSO phase. The dotted lines represent the location (longitude) of maximum correlation at each time lag. The green and violet represent the positive and negative phases. The right panel shows the propagation for EP ENSO positive and negative phases. Note: The designations employed and the presentation of the material on this map do not imply the expression of any opinion whatsoever on the part of Research Square concerning the legal status of any country, territory, city or area or of its authorities, or concerning the delimitation of its frontiers or boundaries. This map has been provided by the authors.

\section{Supplementary Files}

This is a list of supplementary files associated with this preprint. Click to download.

- SupplementaryMJOinterannualvariabilitypaniniroxy20nov2020.docx 